\section{SPRU}

Science and Technology

Policy Research
Working Paper Series

SWPS 2014-08

May, 2014

\title{
Community-based digital fabrication workshops: A review of the research \\ literature
}

Sabine Hielscher

and Adrian Smith 


\section{SPRU Working Paper Series}

The SPRU Working Paper Series aims to accelerate the public availability of the research undertaken by SPRU-associated people of all categories, and exceptionally, other research that is of considerable interest within SPRU. It presents research results that in whole or part are suitable for submission to a refereed journal, to a sponsor, to a major conference or to the editor of a book. Our intention is to provide access to early copies of SPRU research.

\section{Editors}

Tommaso Ciarli

Daniele Rotolo

\section{Associate Editors}

Florian Kern

Paul Nightingale

Matias Ramirez

Joe Tidd \&

Carlos Sato

Maria Savona \&

Mariana Mazzucato

Andrew Stirling Transitions

Caitriona McLeish

Civil military interface

\section{Area}

Energy

Development

\section{Contact}

T.Ciarli@sussex.ac.uk

D.Rotolo@sussex.ac.uk

Science, \& Technology Policy

Technology Innovation Management

Economics of Technological Change

M.Savona@sussex.ac.uk

M.Mazzucato@sussex.ac.uk

A.C.Stirling@sussex.ac.uk

C.A.McLeish@sussex.ac.uk

\section{Administrator}

Jenny Lieu

J.Lieu@sussex.ac.uk

\section{Disclaimer}

The works available here are the responsibility of the individual author(s) and do not necessarily represent the views of other SPRU researchers. As matters of policy and practice, SPRU does not endorse individual research contributions.

\section{Guidelines for authors}

Papers shall be submitted in pdf or Word format. They should contain a title, an abstract, and keywords. Papers should be submitted to one of the Editors, who will process them and send them to the appropriate Associate Editor. Two members of SPRU will be asked to provide a short written review within three weeks. The revised versions of the paper, together with a reply to the reviewers, should be sent to the Associate Editor, who will propose to the Editors its publication on the series. When submitting the authors should indicate if the paper has already undergone peerreviewing, in which case the Associate Editors may decide to skip internal review process.

\section{Website}

SWPS: www.sussex.ac.uk/spru/research/sewps

IDEAS: ideas.repec.org/s/sru/ssewps.html 


\section{Community-based digital fabrication workshops: A review of the research literature}

Sabine Hielscher and Adrian Smith

April 2014

\section{Contents}

1. Abstract

2. Introduction

3. 'Community-based digital fabrication workshops'

3.1 What are community-based digital fabrication workshops?

3.2 Excited claims: Practitioner aims and observer aspirations in community-based digital fabrication workshops

3.3 What networks do community-based digital fabrication workshops create?

\subsubsection{Introduction to Hackerspaces}

3.3.2 Introduction to FabLabs

3.4 Reflections on the literature

4. Grassroots digital fabrication technologies and infrastructures

\subsection{Grassroots digital fabrication technologies}

4.1.1. Introduction to 3D printers

4.2 Infrastructures derived from digital fabrication

4.3 Reflections on the literature

5. Past research on community-based digital fabrication workshops

5.1. Past research on workshops

5.1.1. Methodologies of past research

5.2. Reflections on the literature

6. Community-based digital fabrication workshops: Debates and themes and lesson from existing research

6.1. Debates and themes within the literature

6.1.1. New industrial revolution?

6.1.2. Personal manufacturing and mass customisation

6.1.3. Democratising manufacturing/innovation

6.1.4. New conceptions of labour, skill and creativity

6.1.5. Workshops as a novel cultural, political and social movement?

6.1.6. Debates around sustainability in the context of GDF

Each section includes reflections on the literature

7. Analogies with other technologies and movements

7.1.1. Reflections on the literature

8. Discussion \& conclusion

9. References 


\begin{abstract}
Community-based digital fabrication workshops (such as Hackerspaces, FabLabs and Makerspaces) are innovative spaces where people come together to learn about and use versatile digital design and manufacturing technologies and create things in collaborative projects. Some spaces are run voluntarily, whilst others receive institutional support (e.g. from universities and libraries), but all share an ethos towards providing workshops that can be freely (at least in parts) accessed by the wider public. Workshop members are involved in a variety of practices in these spaces, and that go beyond tinkering with technologies and making things, to include experiments in principled ideas for commons-based peer production that some observers claim might be relevant for a post-consumption society. Nowadays, workshops constitute a global network: they can be found in many major cities around the world; many of them network and share projects and knowledge through social media; and meet up physically at international events.
\end{abstract}

Excited claims are made for community-based digital fabrication workshops. It is argued they address issues of democracy and inclusivity; topics of sustainable production and consumption; and cultivate more creative, skillful and innovative engagements with technology. Such claims appear highly speculative. After all, innovation as an activity involves risks and uncertainty, is destructive as well as creative, and - depending on who appropriates benefits - can exclude certain social interests.

Conducting an in-depth literature review on grassroots digital fabrication, this working paper aims to examine existing analytical themes, methodologies and debates addressed by previous research work relevant to community-based digital fabrication workshops. Our review provides reflections on three critical issues: sustainability, inclusivity, and creativity. Conclusively, the paper draws out existing research challenges when examining communitybased digital fabrication workshops and future research possibilities in relation to the three critical issues. Future research activity must be attentive to these critical issues confronting grassroots digital fabrication.

Keywords: Grassroots digital fabrication, community-based workshops, sustainability, creativity, inclusivity

\title{
2. Introduction
}

A combination of rapid advances in digital design and fabrication technologies with the emergence of social movements for collaborative production and consumption is extending the possibilities for civil society contributions to innovations. Conventional craft activities are also evident in workshops, also linked through social media. Meanwhile, rapidly growing numbers of individuals, firms, and civil associations are exploring grassroots digital fabrication technologies within community-based workshops (such as Hackerspaces and FabLabs). These are networked spaces where these social and technological developments find an engaging practical expression, in the sense that they involve voluntary associations of people coming together and learning how to make things in self-directed projects using digital fabrication technologies and platforms. 
Some advocates have argued that community-based digital fabrication workshops inherently address issues of democracy and inclusivity; topics of sustainable production, consumption and relocalisations of manufacturing; and debates of more creative and, skilling technologies (Bauwens 2006; Schor 2010; Söderberg 2013). Members of these workshops are said to critically design initiatives that:

1) Recalibrate innovation processes towards social and environmental goals, because grassroots innovation capabilities are mobilised to address wider normative goals, addressing issues of sustainability,

2) Relocate innovation capabilities, because workshops allow for shared learning and exchange of knowledge, empowering a wide variety of people to pick up making skills that relate to issues of creativity, and

3) Reconfigure access and participations in innovation processes, because communitybased digital fabrication workshops have the potential to allow for dispersed innovations that are collaboratively produced, highlighting issues of inclusivity (for more information on these themes see Smith et al. 2013).

Arguably, notions of sustainability, inclusivity and creativity are neither inherent in these digital fabrication technologies nor the workshops where they are used. Workshops may allow affordances towards incorporating such issues, but such considerations are not automatic or predestined. As such, these workshops suggest sites where research and practice can explore and co-produce agendas for an innovative civil society. Such activity must be attentive to critical issues confronting community-based grassroots digital fabrication. In the end, whilst an innovative civil society may be concerned about certain social and environmental issues, grassroots innovations as an activity are not inherently sustainable, and can potentially be disempowering and exclude some social interests.

This working paper reviews the current literature on grassroots digital fabrication and community-based digital fabrication workshops in order to reflect critically on the issues of inclusivity, sustainability, and creativity. ${ }^{1}$ Moreover, its aim has been to explore existing analytical themes, debates, and methodologies addressed by previous work into grassroots digital fabrication technologies and community-based digital fabrication workshops. Our review consequently points out gaps in the literature, draws attention to research challenges when examining workshops, and reflects on future research possibilities. It is important to point out that this is not a review of theoretical literatures that might be appropriate to analysing community-based digital fabrication workshops. The literature includes journal articles, popular books, and grey literature. It was undertaken between October 2013 and March 2014.

Whilst conducting the literature review, we encountered several challenges that highlight some of its limitations: 1 ) bounding the literature on community-based digital fabrication workshops and grassroots digital fabrication technologies; 2) bringing together a variety of sources such as academic, activist, and media ${ }^{2}$ writings (some authors work across these

\footnotetext{
1 The scope of this literature review does not extend to dispersed design and manufacturing in general, but simply to community-based and grassroots forms.

2 Media articles have mainly been excluded in this literature review.
} 
categories); 3) making distinctions between the current hype on digital fabrication (in particular, 3D printing) and discussions of people examining and working with these technologies; and 4) including some of the emerging literature, in particular current PhD work and conference sessions that can be difficult to find. Considering these potential limitations and noticing that this is a 'literature-in-the-making', we regard this as a working paper for which we welcome any feedback and additions. We would also appreciate if others want to share their reviews of the literature with us.

This literature review is structured as followed: Sections 3 and 4 introduce communitybased digital fabrication workshops and grassroots digital fabrication technologies and infrastructures, as described in the current literature. Section 5, goes on to outlining the themes and methodologies of past research into community-based digital fabrication workshops and grassroots digital fabrication technologies. Section 6 then details how the current research addresses these themes and delineates some of the debates, before section 7 tries to make some analogies with past technologies. After each section, a short reflection on the current literature is added. Finally section 8 , draws out some overall reflections for future research in the area of sustainability, creativity and inclusion.

\section{Community-based digital fabrication workshops}

\subsection{What are community-based digital fabrication workshops?}

An inspiration underlying the rapid growth of community-based digital fabrication workshops has been the way the internet, web 2.0, and digital culture have opened up and transformed knowledge production and the fabrication of physical artefacts in recent years. Such workshops are diverse spaces where people come together to learn about, innovate, use, and develop digital technologies and conduct projects that involve art, design, engineering, and science. The turn to hardware outcomes (moving from 'bits' to 'atoms') within these communities has allowed members to modify, personalise and manufacture anything from toys and vehicles to 'wind turbines, solar energy systems, and even prefab houses using cheap materials' (Schor 2010, p.122).

A variety of people (from hackers ${ }^{3}$ to hobbyists) have joined these workshops, sometimes labelling them as 'maker communities' (Ree 2011). Others have considered such communities to be part of the 'peer production movement', emphasising the more recent development of a socially-oriented character of the workshops (away from the sole hacker in his bedroom and DIY hobbyist in their garage). Emphasis rests in bringing people together in collaborative projects where they innovate and learn together. The exchange of knowledge and sharing of digital fabrication technologies on an open-source basis is key to their collaborations. In creating physical spaces where people can meet up and share their experiences and skills, so they can reflect and discuss the purposes and wider consequences of their activity (Moilanen 2011). Lipson and Kurman (2013, p.50) have described the ethos

\footnotetext{
3 'Hardware hacking' has several definitions but often refers to the modification of hardware appliances or electronic products to perform functions for which they were not originally intended. This can include software replacement within hardware to the development of electrical circuit changes.
} 
of workshops participants as including topics such as 'community, creativity, social change, and problem solving'. ${ }^{4}$

Over the past few years, these workshops have attracted increased attention from media, public, government, businesses, and academia because their activities and projects have been linked to narratives about a digital revolution in fabrication (a revolution not only associated with technologies and producing things but tightly interlinked with social factors and goals). Efforts towards open source, creative commons, peer-to-peer networking, decentralised/ personal/micro manufacturing (such as people producing their own objects in their own home or near to them), non-market and decentralised patterns of production, and collaborative working have been interpreted as being part of a 'third industrial revolution' (Anderson 2012), 'revolution 'in the making' (Ree 2011), and 'major new sociotechnical system in the making' (Birtchnell \& Urry 2012).

Such rhetoric might not come as a surprise when considering Ree's (2011, p.18 drawing on Turner 2006) statement, 'major advances in digital technology are often born out of grassroots 'countercultural' movements.' Analogies are being made to the development of personal computers by enthusiasts in their garages to illustrate this point and to demonstrate the potential impacts of community-based digital fabrication workshops. Moreover, Walter-Herrmann and Büching (2013) have argued that digital fabrication technologies do not only have a techno-economic role to play in the near future but will also have an impact on different social fields (such as, work and home), in particular, when they are located in community-based workshops. Such impacts are said to facilitate opportunities for sustainable consumption (see, for example, (Schor 2010)), reductions in transportation worldwide (Birtchnell \& Urry 2012) and enhance educational systems, just to mention a few.

Developments have been associated with the emergence of the collaborative economy, including ideas such as commons-based peer production (Benkler \& Nissenbaum 2006), open innovation (Chesbrough et al. 2006), crowdsourcing (Howe 2009), and wikinomics (Tapscott \& Williams 2008). Activities in community-based digital fabrication workshops have been considered to put into question a number of conventions, including: the sources and systems of innovation, intellectual property and patent rights (see for instance P2P foundation), patterns of co-production (Birtchnell \& Urry 2012), conceptions of labour (Söderberg 2013), and the notion of authenticity in craft practices (Ree 2011). Such rhetoric has created a real hype around grassroots digital fabrication, which sometimes risks extrapolating and inflating claims without considering participants' own activities, aims in setting up spaces, and motivations for joining these workshops.

\subsection{Excited claims: Practitioner aims and observer aspirations in community-based digital fabrication workshops}

The hype towards grassroots digital fabrications technologies and their potential social consequences has particularly derived from observers rather than workshop participants' aims and ambitions. This hype is expressed in Lassiter's (2013, p.252) statement,

\footnotetext{
4 Participants get involved in community-building, cultivating skills and capabilities, sharing and collaborative practices, building up their own and other's knowledge, and maybe even exploring concepts like citizenship, democratic production and sustainability.
} 
'The cost and complexity of digital fabrication technologies are coming down very quickly, bringing the tools and capabilities for invention and innovation within the reach of almost anyone, almost anywhere in the world. That kind of democratic, distributed capacity is revolutionary. It promises to change everything... the way we design, manufacture, finance, communicate and market for business, supply chains, the platforms upon which we build businesses, the way we educate and conduct research.'

Although this rhetoric about digital technologies exists there are also voices, who oppose such views and warn against such hype, in particular, when considering past trajectories of other novel technological breakthroughs (Ree 2011) (such as the promises of a paperless office (Sellen \& Harper 2003) and flexible specialisation in manufacturing (Sabel \& Piore 1984)). Moreover, a diverse set of workshops exist such as TechShops ${ }^{5}, 100 \mathrm{k}$-Garages ${ }^{6}$, FabLabs, Telecottages, Innovation laboratories, Coworking spaces, Media labs and Hackerspaces (Troxler 2011). The aims and motivations of these workshops and their participants vary, not all have the ambition to realise the visions described in such media hypes. Some of the workshops orient their activities solely towards the pragmatic and practical side of experimenting with digital technologies and develop norms and practices that reflect such intentions.

Yet, other workshops do have more of a social and political agenda, in the sense that they connect practical projects to counter cultural ideas. This can include a wide spectrum of activities from trying to engage a wider variety of people in novel technologies (such as educational goals, doing outreach work towards vocational courses) to pursuing wider social transformational visions (such as sustainable futures). Political interest can be based on 'questions about who controls technology and how technology is involved in power relations' (Carstensen 2013, p.59) and can form an important identity of a lab (such as the members of the St. Pauli's FabLab, who are concerned about local gentrification issues, social inequalities, and over-abundance and therefore are keen to develop alternative economies, democratising education and technology).

Hunsinger (2011, p.9) has argued that some workshops have gone beyond a model of 'learning to do' (i.e. problem solving to create things) and actually engage in 'learning to become' (i.e. pursuing wider social and political agendas),

'Various global concerns are very apparent in hacklabs and hackerspaces websites... A few websites are very clearly engaged in issues of sustainability and environmental preservation, their projects to some extent reflect that. Other websites are very interested in the open knowledge movement, open source software, and the Creative Commons copyright regime.'

\footnotetext{
5 'TechShop is a group of workshops that are equipped with typical machine shop tools (welding stations, laser cutters, milling machines) and corresponding design software. Access to the workshop is through monthly or yearly membership, and courses on how to use the tools are offered. TechShops started in the California Bay Area, and is present in five more cities around the U.S.A.' (TechShop website) but are currently spreading more globally.

6 '100k-Garages is "a community of workshops with digital fabrication tools for precisely cutting, machining, drilling, or sculpting the parts for your project or product, in all kinds of materials, in a shop or garage near you". Most of these workshops are located in the U.S.A. and Canada (about 180), with five shops in Europe and two in Australia' (Troxler 2011). As opposed to the other examples, 100k-Garages are providing professional manufacturing service, rather than offering shop access to makers.
} 
Aims, including social and political ambitions, frequently depend on 'the history, founders, current and past members of the workshop' (Hunsinger 2011, p.2) but also on the funding sources of the workshop activities. Such funding for the set up and running of the workshops vary, relying on either public funding and/or membership fees (Troxler 2010) and can therefore partly shape the activities and aims. For instance, publically funded workshops (hosted by public institutions, such as schools, libraries, or universities) are not totally independent and somewhat need to comply with their hosts or funders ideas. These workshops are usually expected to be self-funded after a couple of years and therefore have to find commercial models to keep going that potentially conflict with some of their original ideas for the space. In some of the workshops the boundaries between commercial and independent activity has become blurred. This situation has led to some members questioning whether some of the more commercial workshops (that offer, for example, prototyping facilities to business) should still be part of the network (Moilanen 2011). Other workshops have even resisted such moves to keep their independence but as a result have fewer resources to support their activities.

Considering those potential conflicts and the diversity in aims, it is difficult to see how workshop participants are able to fulfil the rhetoric described in the hype. Even when workshops have strong social and political ambitions and try to incorporate them into their project, such translation processes are not always straightforward (such conflicts are discussed in more depth later on). Moreover, such interests are less apparent in everyday workshop practices and participation, compared to the 'revolutionary approaches' and goals, than often portrayed in the media (Walter-Herrmann 2013, p.42). Still, the rhetoric, participants' ambitions, and translation processes might have an important role to play in the development of digital technologies and its impacts on society, considering that these efforts play a part in framing both thinking and action in digital fabrication. Moreover, the workshops are part of a global and networked phenomenon in which norms, ambitions, and aims are discussed and learning is exchanged, creating a sense of 'unity in diversity'. Such networks are the topic of the next section.

\subsection{What networks do community-based digital fabrication workshops create?}

Workshop participants do not only operate locally and in isolation but are also connected to a global network. They discuss issues and share learning through social media online, as well as meeting-up at conferences and events. Groups of workshops that share similar ideas and activities and have a combined process of setting up a space, regularly create interwoven global infrastructures. Within these infrastructures, they can organise events, discussion forums, web tutorials and competitions. Some of these networks are more organised and structured than others, for instance, some have developed manifestos and training programmes (such as FabLabs) whereas others allow for a more ad hoc development of their networks (such as Hackerspaces) (Hunsinger 2011). Members within the networks not only share their learning and experiences but also collaborate on projects. For example, the participants of the FabFi project, including FabLabs in Norway, Greece, South Africa, and Afghanistan, have tried to design and construct free and accessible internet systems accessible to anyone, anywhere. Similarly, the creation of the FabLab Eco-house drew together a variety of different workshops (such as Fablabs in Spain, Lebanon, and Ethiopia) to be able to build an energy self-sufficient, personalised and customised living space. 
Analysing websites, wikis, and blogs of Hackerspaces in order to explain how workshop members learn together and collaborate, Hunsinger (2011, p.1) has found 'that not only is the personal learning environment social, but it is also... transnational, and perhaps even cosmopolitan'. According to Hunsinger (2011), members are closely linked to their local workshop and cooperate regionally with other spaces to share equipment and information and see what other workshops are doing. Further, they make use of two forms of information tools: 1) self-installed open source systems ${ }^{7}$ and 2) web-based services ${ }^{8}$ (Hunsinger 2011, p.7) to connect and collaborate with a global network of workshops. Such tools are often linked to two sites, Wikipedia and the workshops' own website.

For Hunsinger (2011, p.7), the use of these tools and sites provide a close link between workshops online and offline interactions, for instance, the use of video cameras to share real life information about workshops to remote viewers via the internet,

'There non-online life interactions feed significantly back into their online interactions and beyond that they build systems on top of their online life interactions that give them information in their everyday non-online life.'

Such tools, technologies, and sites create 'shared information pools' between workshops members, regional spaces and the global network of workshops to 'create commonplaces where their community can come together and inform others on the nature of their own organisation' (Hunsinger 2011, p.8). Hunsinger (2011, p.8) has argued that such 'commonplaces' help workshop members to develop an 'awareness of the similarities and differences amongst and between hacklabs on an international scale', to interpret and distribute 'norms and practices across hacklabs', and to create 'a common humanity and shared responsibility'. Though, he (2011) has also pointed out that such activities are not practiced by all workshop members and spaces.

In particular, the network of Hackerspaces, but also FabLabs has gained an increased public, media and academic interest over the last years. These workshops are outlines in more depth in the next two sections.

\subsubsection{Introduction to Hackerspaces}

Hackerspaces started in the late 1990s and have become more widespread in the second half of the 2000s (Moilanen 2011). Moilanen (2011) has pointed to a recent shift within the history of Hackerspaces, and identified three waves in their history. The first one occurred during the 1990s and was characterised by attempts from hackers to move from their homes into larger physical spaces where they could meet. The second wave happened during the late 1990s. Some spaces were already established and first discussions about the ideological and theoretical development of Hackerspaces emerged. Some of the hackers were keen to be open about their work (in particular, through promoting free access to the internet) and wanted to gain some wider recognition for their activities. The third wave

\footnotetext{
7 'Mediawiki, which is the wiki software developed in conjunction with Wikipedia, Durpal, which is content management and group management software, or Wordpress, which is blog engine software'. (Hunsinger 2011, p.7)

8 'Such as Wikipedia, Flickr, Facebook, Ustream, and similar project.' (Hunsinger 2011, p.7)
} 
started at the beginning of 2000s. Hundreds of active Hackerspaces have now been established and more are under construction, creating a diverse set of spaces that are bound together through a shared 'hacker ethic' (Levy 2001).

Since 2007, several events and talks have enabled the steady development of new Hackerspaces all around the world. For instance, a project called 'Hackers on a Plane' brought together hackers from the USA and Europe. They toured each other's spaces and deliberated over aspects of how to build a Hackerspace. Discussions became more globally shared and coherent through setting up the hackerspaces.org website, which in 2011 developed into the slogan: 'build! unite! multiply!' (hackerspace.org 2011). Areas of discussion have focused on topics such as 'free software development, computer recycling, wireless mesh networking, microelectronics, open hardware, 3D printing, machine workshops and cooking' (Maxigas 2012, p.5). Hackerspaces have started to focus on the more social aspects of their activities in the virtual and physical world, and created and maintained physical spaces that are regarded as 'community centres' (or 'third places ${ }^{9}$ ), to 'facilitate and foster broader, more creative interaction' within their own locality (Moilanen 2011, p.8).

Today, the Hackerspace community encompasses about 400 member locations all around the world - half of them are under construction or inactive (Troxler 2010). A coherent and agreed upon definition of Hackerspaces does not exist within its own 'community' or in the academic literature (which is still scarce) (Moilanen 2011). After conducting a global survey of Hackerspaces, Moilanen (2011) has come to suggest that most participants do not want to rigidly define the community and its activities, and even regard the non-demarcation as one of its main features. Moreover, some of the members are concerned about nonmembers reactions to the word 'hacker' (considering past connotations to illegal activities when referring to the term), and therefore prefer not to use it. Several definitions have therefore evolved over time with varying emphasis on the spaces' activities, ethics and aims. Although this is the case, in his study Moilanen (2011) derives at several criteria to which most of the Hackerspaces comply: 1 . They are self-declared communities that are independent, not for profit and membership based (i.e. the set up, ownership and governance of Hackerspaces are within the hands of its members); 2. Members have a common space in which they share their tools and knowledge; 3 . Activities often have a strong emphasis on technology and science issues that are explored through processes of trial and error and sharing information; and 4. The space is open to the public (at least for some of the time) (Moilanen 2011).

The life of a Hackerspace is influenced by the way it evolves, mixes with others and branches out into other areas and groupings, whether the space currently lives, hibernates or dies (Moilanen 2011), and how it has been set up and is being run (Maxigas 2012). These developments partly depend on the members' interests, efforts and aims (e.g. not all members are interested in the same set of technologies such as phones, hardware, biohacking and games), their projects (e.g. whether they are collaborative or not), their relations to other workshops, and their workshop governance structure. Investigating these structures, Kera $(2012$, p.2) has argued that

${ }^{9} \mathrm{~A}$ third place is a social setting that is not home or work (Moilanen 2011). 
'The physical location of the space (from industrial buildings to office spaces, private garages or even heritage houses) or legal status of the organisation (non-profit, company, informal gathering) are secondary to the actual processes of governance and innovation, which are rigorously tested and described on the wiki'.

An open membership model has been advocated from the start, including the engagement with old and more novel technologies and the focus on learning, sharing, and cooperation. Membership fees and donations (without any conditions attached) seem currently to be the most preferred way of funding workshops and projects. Company donations and government support mechanisms are frequently associated with losing the independent status of workshops, as members might have to comply to several conditions attached to the support, and therefore are a less preferred option (Moilanen 2011).

The ambition to keep workshops independent from other institutions is also partly reflected in members' motivations to join and be part of a space. In addition to wanting to meet other like-minded people, and to have fun together, members often have altruistic motivations for joining a workshop and a strong commitment to the community (Moilanen 2011). A typical Hackerspace member ${ }^{10}$ spends on average about ten hours a week on Hackerspace related software and hardware projects. Although most members are not keen to develop a shared definition of their activities (and even create a shared manifesto) the collection of members and 'micro' spaces are interwoven, networked with each other and make up a global, transnational community (Kera 2012).

'The global network is simply a platform that enables hackers worldwide to share best practices concerning how to manage independent spaces based on open access, open source software and hardware ideals, while working on their individual and collective prototypes' (Kera 2012, p.2).

Common activities (and their magnitude) vary between members and spaces. They consist of sharing information, knowledge and equipment, conducting competitions (such as 'Hackathons', 'Call-ins', and 'Tuesday meet-ups'), visiting each other's spaces and collaborating on projects and discussions concerning the development of the community. These events have an educational character, intending to address numerous skills and technical issues (such as soldering skills, biohacking, and programming languages) (Moilanen 2011). In addition, they are important to confirm social ties, 'to perform and thus confirm what are otherwise more frequent, though more prosaic forms of virtual sociality... [and in the process highlighting] how social enchantment and moral solidarity... is central' to their activities (Coleman 2010, p.47).

The next section introduces Fablabs (as an additional example of a community-based digital fabrication workshop). FabLabs can be considered to be similar to Hackerspaces, but are conceptually embedded in a more common set of requirements and technologies, as outlined in the FabLab charter.

10 'The typical hackerspace member is a 27-31 (29\%) years old male (90\%) with college level or higher education, committed to one hackerspace' (Moilanen 2011, p.8). 


\subsubsection{Introduction to FabLabs}

In 2013 there were 125 established FabLabs in 34 countries that form alongside Hackerspaces an additional global initiative of workshops. Although there is no real formal process of setting up a FabLab, all of them have evolved from the first lab that was established as part of MIT's Interdisciplinary Centre for Bits and Atoms course, entitled 'How to Make (almost) Anything' (Gershenfeld 2012; Gershenfeld 2005) in 2002. FabLabs are conceptually embedded in a common set of requirements, technologies and processes outlined in the FabLab Charter (Troxler 2010). The charter highlights some of the FabLabs' principles: 'to empower, to educate, and to create 'almost anything' (Nunez 2010, p.24) and beliefs: to provide open access to technologies and workshops, to encourage open and free knowledge sharing, to recognise the protection of intellectual property rights, to take responsibility for the care of machines and others, and to support the FabLab's activities (see Fab Charter).

As pointed out by some of the workshop participants, FabLabs are spaces where anyone can learn about and use digital fabrication technologies to make almost anything.

'They are places where an object can be produced, from its first idea to its digitalisation to its materialisation, and where the objects' biographies become transparent' (Büching 2013, p.117).

For Troxler (2010, p.9), FabLabs primarily provide access to facilities (i.e. 'facility model') or innovations support (i.e. 'innovation support model') to their workshop members. They are open for businesses, entrepreneurs, and the general public, where they can pursue commercial and private endeavours, and come with their own workshop manager (Troxler 2010). Organisational structures and funding sources vary between FabLabs. Some of the labs were able to create independent entities, whereas others are hosted by schools, universities, or innovation centres. Funding often comes from public sources or from the host, attached with the condition that labs start to self-fund themselves after a few years. These conditions have partly led to FabLabs taking up numerous commercial activities, creating 'private-collective (hybrid) innovation' models (Troxler 2010, p.16). Such models are not straightforward to develop and often introduce tensions into the running of the workshop in particular, ' when looking for funding to sustain their ability for private investment while keeping the results open - i.e. gratis and accessible - to the community' (Troxler 2010, p.13). As a result, FabLabs have not created recognised business models that are being replicated.

Although FabLab managers are keen to open up the workshop space for a variety of user groups (such as researchers and general public) (Troxler 2010), a survey of FabLabs has shown that most labs mainly attract 'well educated' and 'technology interested' people, who look for a space in which they can 'tinker' with digital technologies (Walter-Herrmann 2013, p.42). Similarly, Carstensen (2013), who has conducted interviews with members from the St Pauli Fablab, has found that participants usually have a passion for advanced technologies, experimenting and problem solving. Therefore, not all demographics are represented in the labs. Such exclusions can occur because of the labs' 'geographical location, the opening hours, (sometimes) the fees, their institutional context (whether they 
are connected to university, connected to a creative milieu or mainly used by business), and culture' (Carstensen 2013, p.56). Some of the labs have tried to proactively reach out to under-represented groups (such as Manchester FabLab and Sustainable South Bronx FabLab) but this community outreach and development work requires resources and active effort which not all labs can build into their day-to-day activities.

Similar to Hackerspaces, FabLabs have created a global network (i.e. the International FabLab Association, established in 2011). It mainly provides educational, logistical, operational and financial support to each lab. For instance, it gives support for sharing learning and collaborating in projects in a relatively structured manner through video conferencing systems hosted by MIT, scheduled conferences (i.e. the International Fab Forum and the Symposium on Digital Fabrication), the set up of national and international Fab Foundations and the Fab Academy training programme (Walter-Herrmann \& Büching 2013). Walter-Herrmann's (2013) survey on FabLabs has shown that relationships between labs are generally 'informal' (based on project collaborations and friendships, occurring via email or face-to-face interactions) and takes place within their own continent (rather than globally). These relationships can be grounded in strong and lose ties but is often characterised through the exchange of ideas and information (Walter-Herrmann 2013). Similarly, Troxler $(2013 ; 2010)$ has suggested that labs rarely made use of the possibilities the FabLab innovation ecosystem offers' $(2010, p .8)$ and therefore the global network of labs currently 'struggles to define its form and purpose' (2013, p.181).

\subsection{Reflections on literature}

Considering that community-based digital fabrication workshops are extremely diverse in their governance structures, funding sources, histories, members' interests, activities, and aims, we need to be sensitive about how we define the various self-defined workshops (such as Hackerspaces) as 'transnational networks'. Even workshops that self-define as FabLabs, say, and follow the Charter, are in themselves are very varied. It is difficult to say in how far talking to a few workshops in depth provides insights into the network as a whole. Although formal networking events and activities exist and seem to be considered as key elements for the networks' development, most of the interactions are still based on informal interactions where purposes and aims of the overall network are loosely shared. Rather, the (dynamic) networks that exist seem to constitute a shared resource for workshops to draw upon and contribute to as they see fit, rather than a strongly coordinating entity with a clear identity for its members.

Furthermore, this diversity within networks and workshops also requires a more thoughtful approach when trying to frame some of their activities as encouraging inclusivity, sustainability and creativity. For instance only a small number of workshops might directly explore issues of environmental sustainability as a core part of their activity; instead they may be driven by technological problem solving and in the process develop personal rather than social projects. Researchers therefore need to be sensitive towards the variety of political, social and technological claims and aims made for workshops, and which even seem to change over time. Rather than asking how workshops currently address the issues of sustainability, it might be more relevant to examine if and how current activities, discussions and projects relate to such issues. If the research only focuses on community- 
based digital fabrication workshops that relate more centrally and directly to these issues, then research needs to bear in mind that this remains a (small) sub-set of workshops.

One possible way to examine these themes whilst considering current activities, discussions and projects within workshops might be to explore the different cultural dimensions within these spaces: 1) their cultural heritages, 2) the types of cultures that are cultivated and 3) associated countercultural ideas. The reviewed literature on Hackerspaces and Fablabs already demonstrates that workshops often originate from countercultural ideas, such as maker, DIY and fixer movements, anarchist and autonomous movements, and hack cultures that are extremely diverse. For example, hacking has been associated with a 'geek' culture (i.e. young, white men coming together to hack and eat pizza) whereas maker cultures are frequently linked to ideas of citizen empowerment through tools. Although the cultural dimensions are diverse, people come together in workshops where some cultural values are shared. These values frequently are based on counterculture socialisation, such as knowledge sharing that is not grounded in hierarchical institutions and open source ideas that support equal and free access to information. In how far these countercultures are silent in what they do seem to be debated in the literature: Do their countercultural models and counter culture show by themselves social and economic criticism? Although, ideas of culture are alluded to within the current literature, it is difficult to answer this question or delineate the cultural dimensions within these workshops. Further research is required that examines these dimensions in greater depth.

The introduction into community-based digital fabrication sections already uncovers some worthy research themes that are important to study when examining the cultural significance of these workshops in relation to sustainability, inclusivity and creativity. For instance themes, such as 1) the boundaries between commercial and independent activities, 2) the dynamics of learning and sharing knowledge, 3) the relations between online and face-to-face interactions as part of workshops' networking activities and 4) the emphasis on pursuing social and political goals relative to personal project ambitions, and whether these create tensions within workshops and their networks. Furthermore, it is intriguing to explore how the current hype around community-based digital fabrication workshops (also associated to issues of sustainability) actually materialises within participants' activities and projects. Insights from the current literature point to narratives associated with connected, yet distinct spheres: 1) narratives about community-based digital fabrication workshops that is being developed within the media and academic circles and 2) narratives that come from the workshops themselves, which are partly grounded in people physically engaging with digital fabrication technologies in practice.

How are practices and projects within community-based digital fabrication workshops manifesting different narratives and mobilisations of grassroots digital fabrication (and vice versa)? What dynamics and tensions arise between exiting narratives, mobilisations and practices, and how are they negotiated? What role do they play for normative goals of sustainability? Which technologies are out there? And what can people actually produce with them? Such questions point to the need to think more closely about the role of grassroots digital technologies. Therefore, the next section provides a brief introduction to 
these technologies, in particular 3D printers $^{11}$, and current and possible infrastructure derived from digital fabrication.

\section{Grassroots digital fabrication technologies and infrastructures}

\subsection{Grassroots digital fabrication technologies}

The use of computers and other digital technologies in making processes is not novel, as they have been utilised in manufacturing processes since the 1960s (Ree 2011). Here, computer aided design and manufacturing (CAD/CAM) is linked to the use of programmable logic controllers (PLC) that operate the assembly line and fabrication machines. At the time, these technologies were mainly used for rapid prototyping (i.e. visualising and prototyping digital designs) to test the feasibility of products before taking them through the mass production process. Discussions arose about possible futures in which factories would be fully automated and therefore no human presence would be needed on side to manufacture various products (Robben 2013). Critics of such visions pointed out that through increased automation, workers could lose their professional skills, as they would be built into the machine. At the time, workers argued for a production system in which 'human beings can become architects of a valuable production system and not unconscious bees that spawn damaging commodities' (Robben 2013, p.133; Cooley 1987; Noble 1979).

Nowadays, the merger of automated digital manufacturing processes with advanced computer-aided design methods is no longer uncommon and has created rapid (and versatile) manufacturing processes (to be able to construct products, prototypes, and parts), including laser cutters, computer numerical control (CNC) milling machines, CNC routers, and 3D printers. In the case of 3D printers, designers develop computer aided design (CAD) models that make objects through transforming the digital files 'into thin, virtual, horizontal cross-sections and then creat[ing] successive layers until the model is completed' (Robben 2013, p.136). 3D printing relies on digital fabrication processes that are 'additive' (adding materials) as opposed to more traditional methods that are mainly 'subtractive' (removing materials through cutting or drilling). Such additive manufacturing processes allow for the production of near to any complex shape, the innovation of novel materials for the manufacturing process (such as food and bio-materials) and the creation of small and medium size manufacturing batches (considering that there is no longer any need for tooling)(Robben 2013). These technologies allow people to produce products when and where they are needed (such as in space or at home), to create one offs, and to make small changes to a design (such as a fitted, personalised hearing aid piece).

Over the last years some of these technologies have become lower in price and more compact in their design. Researchers, designers, and households have therefore been able to acquire and makes use of these technologies more easily in their labs, studios, and homes. Although these technologies have mainly been used to test and develop prototypes

11 Within community-based digital fabrication workshops 3D printers are one of many technologies used to make things. The combinations and interrelations between these technologies are key when examining digital fabrication. Still, for this literature reviews, 3D printers are discussed in greater depth, as they are regularly portrayed to be emblematic of the intersections between versatile digital fabrication technologies and digital open media, opening up new possibilities for collaborations and democratisation. 
(and are unlikely to replace traditional manufacturing processes in the near future, in particular, when considering their speed of production and still their cost), nowadays, '20 per cent of 3D printing is thought to be of final products rather than the printing of prototypes' (Birtchnell \& Urry 2012, p.4 referring to Kross 2011). In addition to 3D printers, most community-based digital fabrication workshops have laser cutters (able to cut precise pattern into a sheet of material) and engravers (such as Lasersaur an open source hardware laser cutters), CNC routing and milling machines (uses a drill bit (or other type of tool) to cut an object out of a block of plastic, wood, or metal), lathes, 3D scanner, desktop circuit makers, and maybe even sewing, knitting and weaving machines.

\subsubsection{Introduction to $3 D$ printers}

Although a variety of technologies are linked to digital fabrication, 3D printers have gained increased media and public attention over the last few years, in particular, in 2012, with the introduction of the first consumer 3D printer (Barnatt 2013). People have started to use 3D printers in their homes, as they become small-scale personal manufacturers. At the same time, the technology has been associated with the creation of new markets and democratised, decentralised manufacturing, terming it to be an integral part of a 'new industrial revolution' (Anderson 2012). Hype around this trend is partly connected to the idea that this technology can 'make almost anything' anywhere, moving the digital revolution from 'Bits to Atoms' (Gershenfeld 2005). Further, 3D printers have been linked to the 'replicator' machine in the 1980s Star-Trek spaceship Enterprise film that is able to create any object on demand.

Considering this fascination with 3D printers, new, specialised companies (such as '3D Systems' and 'Stratasys') and community-based digital fabrication workshops have been set up to develop and manufacture 3D printers, rather than mainstream consumer electronics. These companies have rapidly grown over the last years,

'2010 saw a step up in corporate investment in this technology. In January 2010, HP did a deal with 3D printer company Stratasys to produce HP-branded desktop 3D printers. In October, Shapeways, a 3D printing service, received a $\$ 5$ million venture capital investment from Index Ventures and Union Square Ventures' (Marston 2011, p.3).

One of the most well known 3D printers, coming from community-based workshops, is the RepRap (i.e. self-REPlicating Rapid prototyper'). ${ }^{12}$ Since 2005, Adrian Bowyer from the University of Bath has developed it with the idea in mind that it would be a self-replicating machine that through its open source licence could be improved by its community over time.

'When we asked Adrian his views on patents, he said. "One of the things that many people engaged in so-called conventional business don't seem to understand is that it's possible to have a company that sells something that is completely open and you can still make a profit.

\footnotetext{
12 RepRap is based on thermoplastic extrusion technology. Although it is meant to be fully self-replicating, this is currently not the case. It requires some fairly standard additional components. The initial design was called 'Darwin', the next model 'Mendel', before developing the 'MendelMax', 'Prussa Mendel', 'Wallace' and 'Huxley' (Barnatt 2013).
} 
People say. 'You don't own any IP. How can you do that?"' He answered his own question: "You have to find a way to add value."' (Lipson \& Kurman 2013, p.232)

Although the RepRap community has created kits so that others could build the printer and developed them further (such as the current 'Mendel' printer), they often did not include all of the parts, making it difficult for people to create their own. Replicating the design of the open-source RepRap printer and creating an easier to use kit, Makerbot ${ }^{13}$ has developed the first full 3D printer kit, called 'The Cupcake CNC' in 2009 (and then created the second version, the 'Thing-O-Matic' in 2012), partly commercialising the RepRap model and loosing some of the open-source ideas in the process (Bohne 2013). 3D printing technologies have therefore been developed within community-based digital fabrication workshops and as part of more commercial endeavours.

Although 3D printers are often put into one category, the technology varies between printers. The main technological difference between existing printers is the way that they build up the object structure. This either occurs through an extruder, a chemical agent, or a laser beam (Birtchnell \& Urry 2012). Similarly to Urry, Barnatt (2013) has identified three categories of 3D printing technologies: 1) Extrusion of semi-liquid materials, 2) Use of photopolymerisation to selectively solidify a liquid with a laser beam, and 3) Adhering particles of powder. ${ }^{14}$ The extruding process is mainly used in today's lower cost 3D printers and is often compared with an inkjet printer that extrudes liquids to print out text on paper. $^{15}$

The most common material used for this process is plastic but some printers can be adapted to use edible materials. Chemical agent and laser beam based printers can also operate with glass, carbon, stainless steel, nylon, metal, ceramic, resin and titanium (Birtchnell \& Urry 2012). Some of the latest printers are able to print an object, consisting of several materials (although this technology is still in its infancy) and colours. Objects take the shape of medical implants, DIY drugs, guns, parts of aircrafts, toys, jewellery, dental crowns, furniture, just to mention a few. Future applications of these technologies are infinite: from printing out objects made out of numerous materials and complex forms (such as electronic circuit boards or programmed materials with new material properties (Lipson \& Kurman 2013), active systems (such as batteries), large structures and vehicles (Birtchnell \& Urry 2012), nano-applications, in situ printing inside the body, custom made food and sweets (Barnatt 2013) to organs, organisms and prosthesis (Lipson \& Kurman 2013).

At present, there are technological and supply chain limitations, for instance, the cost of the raw materials and the printing speed (which is currently still rather slow) that hinder mainstream adoption of 3D printing technologies (Lipson \& Kurman 2013). Additionally, Lipson and Kurman (2013, p.39) have emphasised that 'the 3D printing industry needs a

\footnotetext{
13 MakerBot Industry is a Brooklyn, New York-based company founded in January 2009, producing 3D printers that are modeled on the RepRap project. They have been recently bought up by Stratasys (a large, established manufacturer of 3D printers), which has diminished even more open source ideas and practices (Morozov 2014).

14 Under the extrusion technologies, he has categorised: thermoplastic extrusion, fused deposition modelling of metals, multiphase jet solidification, and material extrusion of wood, concrete, and food. Stereolithography, DLP projection, and two-photon polymerisation are photopolymersiation technologies, whereas material jetting, binder jetting, selective laser sintering, directed energy deposition, electron beam melting, and selective heat sintering belong to the bonding or fusion of powder granules technologies.

15 For a full review of these technologies, their current limitations, and applications see (Barnatt 2013), chapter 2.
} 
user-friendly platform of tools and application or game whose mass appeal will create new markets and attract millions of new users' ${ }^{16}$ Although scepticism over the uptake of this technology exists, some actors such as Barnatt (2013, p.6 onwards) have claimed that 3D printing provides 'clear and significant benefits over exiting technologies and industrial practices' such as 'improving product design' (such as developing complex geometric structures), 'transforming traditional production' and retail, allowing for mass customisation, small production runs, and open design ideas, increasing digital storage and transportation, and finally, 'improving human health' and 'saving the planet'. With regards to sustainability, the use of 3D printers is said to allow for design optimisations, efficient use of materials, reduction in waste, and enhancements in products' functionality (Huang et al. 2012, these environmental, health and social issues are discussed in more depth later on in section 6.1.6). In addition to such suggested technological, design, social, environmental opportunities, novel online business models have aided the process of diffusing digital fabrication technologies, making them more accessible, interactive and entrepreneurial (Ree 2011). These endeavours and the infrastructures that they create for digital fabrication activities are the subject of the next section.

\subsection{Infrastructures derived from digital fabrication}

The current digital fabrication infrastructure consists of small machine builders (some concentrating on personal manufacturing) ${ }^{17}$, online manufacturing shops, website marketplaces for makers ${ }^{18}$, and digital media file sharing websites. For instance, Shapeways is a Dutch founded company which allows users to make, buy, and sell 3D printed items on their website (an example of a hybrid model between a social network side and a digital fabrication manufacturer). Similarly, Ponoko is an online manufacturing service, making use of laser cutting, 3D printing and open-source electronic hardware to make customise objects for their clients. ${ }^{19}$ The company gained attention from the media because of its novel business model, being a manufacturer to realise on-demand and distributed manufacturing services.

In addition to online manufacturing shops, digital media file sharing website have been set up to encourage the open source aspects of digital fabrication and develop an online resource of different digital designs. The idea is to create a 'Universe of Things' (such as Thingiverse and GitHub) that anybody can access and personalise their design. For example, Thingiverse was set up by the MakerBot team so that people could freely exchange their designs. Google's 3D Warehouse, Instructables, Cubify, i.materialise, and The Pirate Bay work on 'similar' principles, providing 'physibles' (a term coined by The Pirate Bay which refers to a digital file that can be used to print out an object on a 3D printer) to anyone who

\footnotetext{
16 '3D Systems annual report stated that between 2010-2011, revenue from sales of mid-and small-sized personal and professional-grade (not industrial-grade) 3D printers increased about 40 percent from the year before' (Lipson \& Kurman 2013, p.40).

17 Small machine builders are companies such as MakerBot, LumenLab Micro CNC, and Bits From Bytes Ltc and consumer 3D printers are, for example, 3D systems Cube and Makegear M2.

${ }^{18}$ Such as Etsy (a website where designers can sell their products) and Quirky (this is how it works: person sends in designs, the community can vote on it, if they are enough pre-orders Quirky designer make design ready for manufacturing, Quirky and initial designer share the profit)

${ }^{19}$ Other online manufacturing shops: Big Blue Saw, eMachineShop, Sculpteo, Materialise, and many others (see Barnatt 2013 for a review).
} 
wants to download the file - just like music and literature downloads (Birtchnell \& Urry 2012).

To ease the access and usability of these technologies, numerous 3D modelling software programmes have been adopted and developed, including professional programmes (such as Rhino) to more tailored ones. The more tailored programmes provide makers with several preferences and parameters from which they can create their object instead of modelling it from scratch (Ree 2011). Here, objects are co-created between the programme developer and the person choosing from numerous preferences to create the final outcome. The objects can therefore be mass customised in numerous shapes, colours and forms.

These online services vary between multi-national companies; start up firms and community based-digital fabrication workshops, applying open source and peer-to-peer sharing values to differing degrees. Most of the start-up firms and software/hardware developments often originate out of the community-based digital fabrication workshops, creating, what Söderberg (2013, p.130) has described as, a 'symbiotic yet constrained relationship' between workshops and companies. For instance, the open source printer from the RepRap community has been closely interlinked with start-up firm MakerBot. MakerBot has modelled their first 3D printer on the RepRap printers but taken only some of the open source values on board. The relationship between the two parties became more tense once the RepRap community realised that some of the parts of their second-generation 3D printer could not be printed on the MakerBot printer. As a result, the MakerBot printer could not be used to print out a RepRap one, at a time, when the MakerBot products gained increased interest. Subsequently, the RepRap community re-designed their printer, in order to encourage their own growth and uptake (Söderberg 2013).

Future ideas for developing the digital fabrication infrastructure envisage a higher dispersal of digital technologies into people's home (i.e. personal fabrication) or the proliferation of 3D printing shops in warehouse, high streets or shopping centres (i.e. micro manufacturing centres). Such developments might originate out of community workshops but might also be part of more commercial activities, and in the process create hybrid formats. ${ }^{20}$

'Intermediaries will not just exist online. There are likely to be commercial versions of FabLab or Hackerspace, the 3D equivalent of Kinkos, that will produce same-day prints for you in a high street location.' (Marston 2011, p.6)

Similarly, Petschow et al (2014) have suggested that grassroots digital fabrication technologies will not necessarily lead to an economy based on commons-based do-it-withothers ideas, but rather be characterised by hybrid formats that create in-between centralised and decentralised, commons and market, etc. spaces. It is possible to suggest that some of these workshops already fulfil some of these more commercial characteristics (such as TechShops).

\subsection{Reflections on the literature}

\footnotetext{
${ }^{20}$ At this point it might also be interesting to point out that members of community workshops have adapted commercial products to develop open hardware designs such as digital scanners that make use of the Kinect for Xbox.
} 
The last few sections of the literature review have shown that digital fabrication technologies are often developed at the intersections of commercial and non-commercial activities, creating 'hybrid formats' (Troxler 2010). Some activities might originate from community workshops that later on get taken up by start up firms (such as technological developments and the creation of infrastructures). These developments can create a close relationship between both parties that nevertheless, over time, can become constraining if the start up firm starts to drop some of the community's ethics and values attached to their developments (Söderberg 2013). Rather than assuming that community-based digital fabrication workshop activities are non-market based, the relationship between commercial and non-commercial endeavours and their interactions with social and political aims becomes an empirical question.

Moreover, it seems that hybrid endeavours have been responsible for producing infrastructures, which ease the use of digital fabrication technologies, making them more accessible to a wider audience. Instead of designing an artefact from scratch within digital design programmes, some software packages allow people to adjust several preferences and parameters from which they can create their object. Although workshops could potentially become more inclusive because there is less of a skill barrier to enter them, some of the social and political ambitions, for instance the commons-based production of digital technologies, might be lost in the process (considering that they are fundamentally based on an in-depth understanding of the technology). In how far such ambitions (including, for instance, the production of social innovations) can be kept whilst at the same time easing the access to these technologies could be an additional empirical question: How do material capabilities and skills link to workshop participants' wider social and political goals? In how far do people need to become makers (with enhanced technological skill and understandings) to be part of the revolution?

In addition to highlighting such relationships and tensions, the above sections draw attention to the current media hype around 3D printers, sometimes dis-acknowledging that printing processes can be based on a variety of technologies and materials. 3D printers are not the only technology that makes up digital fabrication (and in some workshops these technologies are even used in combination with more traditional hand tools). So rather than examining the developments of 3D printers, as a single technology, interactions between technologies are key to the investigation (in particular when wanting to explore current practices and mobilisation within workshops).

Moreover, the above sections have shown that technological limitations within digital fabrication still exist, impacting on the uptake of these technologies and their potential impact on existing manufacturing and production structures. The media hype sometimes makes it difficult to distinguish between the current opportunities and challenges of these technologies. Do writers envisage certain practices in relation to digital technologies or do they actually exist? Not only the rhetoric around digital fabrication technologies and practices in community-based workshops determine the future impact of these technologies but also possible technological limitations that might persist over time. In the past researchers have employed numerous social science methods to examine existing 
practises within workshops and explore possible futures ones through scenario workshops. The next section records and reflects upon some of these research methodologies.

\section{Past research into community-based digital fabrication workshops}

\subsection{Past research into community-based digital fabrication workshops}

Academic literature that examines digital fabrication technologies and community-based digital fabrication workshops is rare, in comparison to the greater amount of media and popular culture text (often using a 'revolutionary rhetoric' to describe recent developments) ${ }^{21}$ and activist writing (although the boundaries between those writings are sometimes blurred) (Walter-herrmann \& Büching 2013). Drawing on Ree's (2011) review of literature that examines 3D printing and related digital technologies, it becomes apparent that current academic work (with a few exceptions) has mainly concentrated on the science and engineering aspects of grassroots digital fabrication technologies (Burton 2005; Hopkinson et al. 2006). ${ }^{22}$

Social science studies are still scarce and the work that does exist has mainly concentrated on the business, technical and industry aspects of developing digital fabrication, rather than on their social, cultural and political implications, and very little indeed has considered the grassroots take up and use of these technologies. ${ }^{23}$ Literature on digital fabrication technologies and community-based workshops has focused on outlining possible future scenarios for manufacturing, in particular, discussing issues of intellectual property and the production of illegal and dangerous objects (for example, Weinberg \& Knowledge 2010); implications for the professional design industry (such as Simpson et al. 2006); and followed the historical development of particular digital fabrication technologies (Jones et al. 2011). Some grassroots uses feature in these scenarios, but it is neither an exclusive nor in-depth focus.

Considering the lack of social science in this topic, academics have drawn on a more broader literature of open source software (von Krogh \& von Hippel 2006; O'Mahony 2003), commons-based peer production (Benkler \& Nissenbaum 2006), labour processes (Söderberg 2013), user-led and open design/innovations (for example, Truffer 2003), maker activities, craft traditions and DIY cultures (for example, Katterfeldt et al. 2013; Robben 2013), hacking and bio(hacking) (such as Levy 2001; Delfanti 2013) ${ }^{24}$ to examine the possible implications of digital fabrication technologies within wider social and political contexts.

Similarly to the work on digital fabrication technologies, academic work on communitybased digital fabrication workshops is still in its infancy. Past research has mainly focused on empirically trying to map the extent and aims of the workshops activities, such as exploring

21 Popular text, for example, (Hatch 2013), (Anderson 2012), etc.

22 See, for example, the numerous additive manufacturing research groups in the UK.

${ }^{23}$ Such limited social science research might explain why the current hype around digital fabrication is currently so little substantiated. There are not a lot of reflections on why people would want to become decentralised producerconsumers, or engage in sustainable, closed loop manufacturing. Further, there is little analysis of the economic, political, social or cultural conditions under which this might arise, and how those conditions might themselves arise out of current situations.

${ }^{24}$ See for example writings on hacker ethic (Levy 2001), often described as 'gift societies' and 'gift economies' (Zeitlyn 2003) 'of informational freedom, antiauthoritarianism, collaboration and creativity' (Haywood 2012, p.9). 
their business models (Gjengedal 2006) and innovation potentials (Troxler 2010) and examining the history, cohesiveness and aims of individual workshops and their networks (Walter-Herrmann 2013; such as Hunsinger 2011; Troxler 2011; Coleman 2010; Haywood 2012). Studies just started to emerge that have reflected on the political, cultural and social motives of participants (such as Maxigas 2012; Magaudda 2012; Söderberg 2013), and whether the activities within workshops can be described as being part of a social movement (Walter-Herrmann 2013).

Nevertheless, it seems that academic social science work on digital fabrication technologies and community-based workshop is on the upsurge, in particular, when considering the increase of conference strands and special issues in journals ${ }^{25}$, the establishment of the Journal of Peer Production, and amount of PhD students ${ }^{26}$ working on the topic. Ree (2011) has pointed out that more recent studies on community-based digital fabrication have examined 'the interrelatedness of technology, materiality and sociality; accounts of craft and making; theories of (the perception of) authenticity; as well as reports of current economic conditions and practices' (including the status of the object and their digital representations ${ }^{27}$ ), drawing on actor network theory and the Social Construction of Technology. Furthermore, researchers have looked to the past to, for example, examining older community workshops, such as Technology Networks in London in the early 1980s, and as part of an earlier movement for socially useful production (Smith 2014).

Considering, the variety of topics academics have studied in more or less depth on digital fabrication technologies and community-based workshops it becomes clear that researchers have drawn on a variety of theoretical approaches, disciplinary topics and philosophers (such as STS and labour processes (such as Söderberg 2010a) and social movement theory (such as Walter-Herrmann 2013)) to examine their practices, debates and issues. Nevertheless, a lot of the researchers seem to merely empirically describe their experiences within these communities, drawing on various themes to make sense of what they have observed. The next section outlines some of the methodologies used within current research on community-based digital fabrication, before reflecting upon possible lessons for our own research projects on the topic.

\subsubsection{Methodologies of past research}

Methodologies on examining community-based digital fabrication workshops have been mixed. Some studies, for example, have examined the global community of workshops, concentrating either on FabLabs (Troxler 2013; Walter-Herrmann 2013) and/or Hackerspaces (Moilanen 2011), through conducting surveys at events or sending them out via emails and forums. ${ }^{28}$ Such surveys were sometimes complemented with qualitative approaches: conducting workshop member interviews, and/or examining particular projects

\footnotetext{
25 Such as the 'From Hobby to Science Work: The Culture \& Politics of Professionalized DIY Making' session at the 4S 2013 conference in San Diego and the 'Hacking STS: bio-hacking, open hardware development, and hackerspaces' session at the EASST 2012 conference in Copenhagen

${ }^{26}$ Such as Zane Kripe, Leiden University; Kevin Gotkin, University of Pennsylvania; and Camille Bosqué, Université Paris-Est Marne-la-Vallée

27 'The digital-material convergence, of which 3D printing is a lead indicator, might impact on the theoretical understandings of terms such as "thing”, "object”, "design" and "digital media”' (Ree 2011, p.87).

${ }^{28}$ Some surveys look at a range of DIY communities (including, Instructables, Dorkbot, Craftster, Ravelry, Etsy, and Adafruit) such as Kuznetsov and Paulos (2010), exploring their motivations, values and shared learning processes).
} 
conducted within the workshops (Troxler 2010), depending on the aim of the study. For instance, Moilanen's (2011) examination of the global Hackerspace network was grounded in a longitudinal survey (sending out two surveys: July 2010 and June 2011), investigating the motivations, values, activities, socio-demographics and interests of members. In addition, he drew on ethnographic methods (such as participant observations), having been a member of a Hackerspace for several years and conducted several surveys. Similarly, Troxler (2010) had a mixed method approach (using interviews, surveys, and case studies) to investigate the activities of FabLabs and the numerous business models developed in these workshops to become self-sustaining.

Moilanen (2011) has pointed to a few practical issues that researchers might experience when conducting surveys with community-based digital fabrication workshops. Firstly, the survey format used might play an important role whether members participate in the study. For example, 'Google Document/Forum' represents a format that some members are opposed to for reasons of commitments to free software and other values, and therefore as a consequence members do not participate. Secondly, Moilanen (2011) had to carefully deliberate through which channels he distributed the survey, mainly using Hackerspace mailing lists rather than social media sites, to be sure that only workshop members would fill in the survey.

In addition to surveys, textual, semiotic and discourse analysis have been used to examine the global network of workshops, through systematically tracing their websites, blogs and discussion forums (such as Hunsinger 2011; Moilanen 2011; Jones et al. 2011). ${ }^{29}$ For example, Hunsinger (2011) conducted a 'multimodal content' analysis (studying videos, pictures, texts, etc. on 220 websites, wikis and blogs ${ }^{30}$ connected to Hackerspaces and Hacklabs that were collected during 2009 and 2010) to better understand how members collaborate and learn from each other in their workshops and as a network. To be able to identify 'primary' websites of Hackerspaces and Hacklabs, Hunsinger (2011) made use of a 'spider' web tool that 'finds all links in the current webpage [and in this case hackerspace.org and Wikipedia pages on Hacklabs and Hackerspaces] and follows them to the next page... creating a network or web of pages that exist within relation to the current page' (an example of a web-based sampling for conducting a content analysis of web-based materials $\left.{ }^{31}\right)$. Another recent study that looked at the chronicles of the development of the open source 3D printer, called RepRap, was grounded in analysing the writings within several blogs and forums (Jones et al. 2011).

\footnotetext{
29 'Hacklabs and Hackerspaces tend to use two types of informational tools that they link to in relation to their web presence. They use self-installed open source systems such was mediawiki which is the wiki software developed in conjunction with wikipedia, Drupal, which is content management and group management software, or Wordpress, which is blog engine software. They also use web-based services such as Wikipedia, Flickr, Facebook, Ustream, and similar project.' (Hunsinger 2011)

30 'These websites comprise around 40000 documents, primarily html files, but they also have pdfs, plain text, and their related materials. It has over 20 million words, and just over 889,000 unique words. The majority of the corpus is in English, but a variety of languages are also present.' (Hunsinger 2011, p.3)

31 According to Hunsinger (2011), 'in this current dataset, the linked materials have been scrubbed from the data, and only the primary website and any websites with the same domain were included. The original list of primary webspaces was derived from the spidering the hackerspaces.org website and the Wikipedia pages on hacklabs and hackerspaces. By spidering the initial list of websites, I was able to compile a clean list of 220 websites. There were several thousand related websites, but these 220 were easily identifiable as being the primary websites of a hacklab or of a hackerspace. These websites comprise around 40000 documents, primarily html files, but they also have pdfs, plain text, and their related materials. It has over 20 million words, and just over 889,000 unique words.'
} 
In-depth studies investigating particular community-based digital fabrication workshops and their associated activities have mainly drawn on case studies and (auto)ethnographic methods. Researchers and activists (for example, Maxigas 2012; Moilanen 2011; Ree 2011) have employed ethnographic methods, often using their own workshop membership to draw on their experiences and observations for their analysis. Such self-reflections seem to be considered as valid and useful in the examinations of workshops. For instance, (Gotkin 2013) has employed ethnographic methods and textual analysis to examine the role of pleasure in hacking ${ }^{32}$; and (Maxigas 2012) has made use of similar methods to differentiate the historical origins of Hacklabs and Hackerspaces. Drawing on Czarniawska-Joerges (2007) work, Haywood (2012) has argued that ethnographic approaches are useful, as the activities of members occur simultaneously in different spaces (for example, within workshops and in internet forums) and through several technological ways, thus challenging the employment of some social science methods. She therefore advocates the use of a 'mobile ethnology', including methods such as 'shadowing', 'diary studies', 'observant participation', and 'following objects' (Haywood 2012, p.2) whilst drawing on 'virtual ethnography' (Hine 2000) and 'multi-mode ethnography' (Marcus 1995). In addition to ethnographic methods, some researchers have conducted critical making seminars within community-based workshops or with a selected few participants to interact with digital fabrication technologies. For example, Ree's (2011) study has examined the impacts of these technologies on the design process through inviting several 'makers' to create an object through the use of digital fabrication technologies and reflect upon the process.

Studies that have connected the use of digital fabrication technologies within communitybased workshops to sustainability issues have either drawn on environmental assessment methods (such as life cycle assessments) to examine the impact of particular digital fabrication processes (for example, the environmental impact of distributed manufacturing using 3D printers (Kreiger \& Pearce 2013) or the impact of open source 3D printers to enable sustainable developments (Pearce et al. 2010) These environmental, health and social issues are discussed in more depth later on in section 6.1.6. Another method to examine the future impacts of digital fabrication technologies, not only in workshops but on personal use in the home, has been the development of scenarios exploring qualitatively several visions. For instance, (Birtchnell \& Urry 2013) used 'science fiction/creative prototyping vignettes' in seminar settings to explore four different scenarios of possible digital fabrication futures (as well as considering the impacts of energy scarcity and climate change on this development). The four scenarios were created by positioning each one on a two-axis diagram: one axis measured people's capacities and practices in relation to digital fabrication and the other axis depicted the spaces and actors where most of the activity will take place (from commercial, home to community centres) (Birtchnell \& Urry 2013; Petschow et al. 2014, concentrating on different level of decentralisation).

32 Gotkin (2013, p.15) has looked towards several disciplines to explore the pleasure of hacking, attempting to explore this in terms of 'beauty, craft, and creativity'. Conclusively he has stated that 'these concepts help us understand why the pleasure of hacking can seem so viscerally familiar to those who have never hacked in earnest before. And yet, why do hackers sometimes prioritise their work over sleeping and eating in ways that other artists do not? The answer is that the creative pleasures that share borders with other activities uniquely manifest in hacking such that they twist and repeat into skein of reward, concentration, and mastery'. Gotkin calls this 'recursive pleasure'. 
Within these methodologies the unit of analysis has varied between examining and comparing certain communities (for example, Maxigas 2012), sub-communities that come together through projects (such as the development of the RepRap printer) (such as Söderberg 2013), particular digital fabrication technologies (for example, Kreiger \& Pearce 2013), the phenomena of digital fabrication (decentralised and/or personal) (such as Petschow et al. 2014) and community-based digital fabrication workshops (Troxler 2011). Outlines of sampling strategies are scarce within the studies; even definitions between them are rare. Some differentiate between community-based workshops, focusing on the diversity of their technologies, economic infrastructure, organisation or governance structure, existing values, differences in access to the public, and the variety of things that are produced within the workshops (Walter-Herrmann 2013).

For example, Troxler (2011, p.4) has attempted to categories and plot various community workshops ('fabbing universe'): Hackerspaces, FabLabs, TechShops, 100kGarages, Sharing platforms, and Open Source Hardware within two dimensions. His aim was about 'trying to identify their business potential and asking how these initiatives contribute to giving people control over their productivity' (Troxler 2011, p.1). The dimensions 'characterise[ing] initiatives as more reproductive or more generative in their nature, and as more infrastructure-orientated or more-project orientated in their approach' (Troxler 2011, p.4) see diagram below.

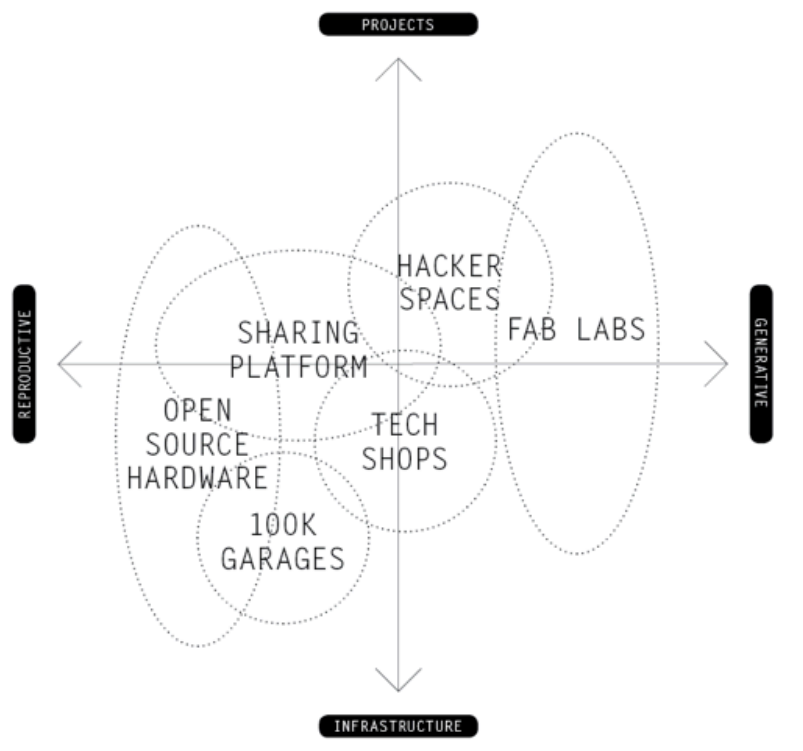

Taken from (Troxler 2011, p.6)

Nevertheless, studies that look across several community-based digital fabrication workshops are still scarce and with it thoughts around how to define, categorise or differentiate their activities, aims, and structure.

\subsection{Reflections on the literature}

Drawing on the above literature, a few practical lessons can be drawn out from past studies and their methodologies that have examined digital fabrication technologies and community-based digital fabrication workshops: 
- Researchers need to consider the format and distribution channels when conducting surveys.

- Researchers need to be sensitive to the diversity of workshops when considering sampling issues and consider that some workshops prefer not to limit and specify what they do. ${ }^{33}$

- A lot of discussions and debates within networks can be followed on the internet (within forums and discussion groups), providing a wealth of information that requires an informed strategy of data gathering and analysis to make sense of the information.

- Activities of members occur simultaneously in different spaces and through several technological pathways, thus challenging the employment of some single site and/or single unit of analysis social science methods.

- A lot of researchers use ethnographic methods within their research, and usually are members of workshops themselves.

Except for a few studies (such as Söderberg 2010b), theoretical reflections and approaches are less discussed within the literature, in comparison to some existing thick, empirical descriptions. Drawing on the literature review, we think that an understanding of community-based digital fabrication might further require the development of a theory centred on the community and their networks. Such inquiry poses questions about the identity, practices, ambitions, and perceived threats and opportunities constitutive of the community (Seyfang \& Smith 2007). A more sociological account of the different mobilisations, practices, and discourses of grassroots digital fabrication in play in community-based workshops might provide a more fruitful analysis. Here, theories and literature from user-led and grassroots innovation, social movement studies, the sociology of technology, material culture can potentially be helpful (Smith et al. 2005; Smith et al. 2013). In addition, these theories need to link to conceptualisations that consider the performance of making things and the materiality of workshop activities (Marres 2012).

Overall, the existing literature highlights a broad set of analytical themes that arise within workshops and the rhetoric surrounding them that require a portfolio of theoretical resources to make sense of this activity. Another route might be to be more explorative with the research. Instead of coming to the research with an existing theoretical lens, academics could rather see what conceptual ideas emerge from the research. Some themes derived from looking at community-based digital fabrication workshops have already been discussed within the sparse social science literature and more popular writing on the topic. These debates and themes within workshops, as described and discussed in the existing literature is the topic of the next section.

\section{Community-based digital fabrication workshops: Debates and themes and lessons from existing research}

\footnotetext{
${ }^{33}$ How can researchers meaningfully define diverse community-based digital fabrication workshops to gain insights into the networks as a whole when conducting their research? How can normative aims within research projects be meaningfully considering without losing sight of workshop members' personal, political, social and technological aims?
} 


\subsection{Some debates and themes within the literature}

\subsubsection{New Industrial Revolution?}

Novel digital fabrication technologies and community-based digital fabrication workshops have been increasingly linked to ideas of an upcoming third industrial revolution (Barnatt 2013). ${ }^{34}$ For instance, Anderson $(2012$, p.41) has argued that

'The dawn of the Information Age, starting around 1950 and going through the personal computer in the later 1970 s and early 1980 s and then the Internet and the Web in the 1990s, was certainly a revolution. But it was not an industrial revolution until it had a similar democratising and amplifying effect on manufacturing, something that's only happening now. Thus, the Third Industrial Revolution is best seen as the combination of digital manufacturing and personal manufacturing: the industrialisation of the Maker Movement.'

Digital tools help makers to easily collaborate with each other, share their learning locally and globally (a process that has been termed 'commons-based peer production' (Benkler \& Nissenbaum 2006)) and further, allows them to fund together manufacturing tools for larger scale processes and projects (through instruments such as crowd-sourcing on sites like 'Kickstarter'). As part of these activities, 'nonmarket production' processes in combination with 'decentralised production and distribution' have started to play a greater role in society (Troxler 2010, p.2).

'Industrial revolution refers to a set of technologies that dramatically amplify the productivity of people, changing everything from longevity and quality of life to where people live and how many there are of them' (Anderson 2012, p.30).

According to Troxler (2013, p.189), community-based digital fabrication workshops can contribute to such a revolution, he has also argued that if members want to be part of 'Making the Third Industrial Revolution', they need to become less concerned with the development of their own projects (i.e. sole practical making issues). Instead workshops and their networks need to think more closely and reflectively about how they want to 'organise the ecosystem' of workshops (Troxler 2013, p.191). Drawing on Hess and Ostrom's (2007) proposed Institutional Analysis and Development framework, Troxler (2013, p.191) has offered a roadmap of questions that could aid the process towards creating a novel form of commons, whilst initiating a third industrial revolution: 'How to build effective forms of collective action and self-organisation for FabLabs?'; 'How to break free from traditional systems and creatively design new systems that tap into the capabilities of FabLabs?'; and 'How to achieve equity and fairness?'.

\footnotetext{
34 In addition to three industrial revolution, Troxler (2010, p.1) has identified three digital revolution to which community-based digital fabrication workshop are linked, 'First there was a digital revolution in communication (from analogue to digital telephony) that eventually cumulated in mobile communication and convergence of media. Then there was a second digital revolution in computation (from analogue to digital computers) that eventually made personal computers possible and lead to a convergence of communication and computing. The next digital revolution, according to Gershenfeld (2005), is in the field of manufactured physical goods with the emergence of digital personal fabrication or 'fabbing.'.
} 
For Rifkin (2011, p.11) such a third industrial revolution does not necessarily derive from the activities of makers but depends on 'new communication technologies converg[ing] with new energy systems'. For example, for him the first industrial revolution revolved around novel iron and steam technologies that aided the textile production whereas, the second industrial revolution was stimulated by the development of electricity, steel and chemicals and at the time increasing mass production (Robben 2013). Now, there is the expectation that current digital technologies (possibly in combination with renewable energy (Rifkin 2011)) will create a third industrial revolution. Nevertheless, Rifkin (2011, p.2) has argued that in addition, to new energy systems, a revolution would require 'reconfiguration of the economic infrastructure' and 'a massive retraining of workers'.

The rhetoric of a 'third industrial revolution' through digital fabrication is frequently linked to other notions that are discussed in more depth below: 1) democratising manufacturing/innovation, 2) personal manufacturing and mass customisation, 3) new conceptions of labour, skill and creativity, 4) workshops as novel cultural, political and social movements, and 5) possibilities for sustainability.

\subsubsection{Democratising manufacturing/innovation}

Bollier (2006, p.35) has argued that, 'the role of social and civic factors in economic production - is becoming a powerful variable in its own right'. This is further highlighted by von Hippel et al (2012) work that has found that 'consumers annual product development expenditures were $f 5.1 \mathrm{bn}$, which is 2.3 times the annual consumer product research and development expenditure of all firms in the UK combined' (in Troxler (2013, p.186)). Such social production processes are often signified by a greater participation of 'nonprofessionals' within design and manufacturing and are linked to open source ideas and the democratisation of innovations and manufacturing. These are topics that are frequently discussed and practiced in community-based digital fabrication workshops (see for example, the developments of the open source 3D printers: RepRap and Fab@Home). ${ }^{35}$ Well-known open source software projects have produced the Linux operating system, the Firefox web browser, and the Apache web server; these processes have also been translated into the domain of culture and education (see for example, Open Street Maps and Wikipedia).

The development of infrastructures, practices and designs for open source hardware can be framed similar to the open source software domain as a 'peer-produced common' (Troxler 2013, p.185; Benkler \& Nissenbaum 2006; Bauwens 2006). Benkler and Nissenbaum (2006, p.1) has defined peer-produced common as,

'A socio-economic system of production that is emerging in the digitally networked environment. Facilitated by the technical infrastructure of the Internet, the hallmark of this socio-technical system is collaboration among large groups of individuals, sometimes in the order of tens or even hundreds of thousands, who cooperate effectively to provide

\footnotetext{
35 The RepRap (www.reprap.org) and Fab@Home (www.fabathome.org/wiki) open source 3D printers are similar in their design. The Fab@Home printer has been developed at Cornell University by Hop Lipson and Evan Malone in 2006 (the 'Model 1' and 'Model 2'). It is based on a syringe based extrusion (rather than nozzle extruder) technique and therefore allows for more materials to be used for the printing process (although the material cannot be deposited simultaneously and the printed object is significantly smaller). The main aim of the project was the democratisation of innovation.
} 
information, knowledge or cultural goods without relying on either market pricing or managerial hierarchies to coordinate their common enterprise.'

Within commons-based peer production (Benkler \& Nissenbaum 2006) and the peer-topeer economy (Bauwens 2006), software and/or hardware outcomes are frequently produced by a group of volunteers (who develop them in their spare time). Such outcomes can develop in many directions, as none of the participants take ownership over it or try to manage its diffusion. Reasons to participate in open source can be social and political but often participants realise that these processes can improve codes, fix designs, improve and market their ideas, and add value by keeping them open for others to modify (Anderson 2012; Sylvester \& Doering 2013). ${ }^{36}$ In addition, they build trusting relationships where people are happy to help each other out. Some commercial activities might derive from the selling of equipment and services attached to the open source software and/or hardware. Still, their overall development is frequently free from market-based developments.

For Benkler and Nissenbaum (2006, p.7), 'peer production is a model of social production, emerging alongside contract- and market-based, managerial-firm based and state-based production'. He goes on and points out that such forms of production are signified by two characteristics. Firstly, people who participate in these activities are often driven by social and political aspirations. Moreover, rather than starting off with specialised teams, peer production projects can draw together a large number of people (with diverse resources, skills and knowledge), potentially increasing the probability to combine the most suitable people to work on each project. Secondly, their activities are not managed through a centralised source. Decision-making processes rely on the collaboration of volunteers (i.e. decentralised) and often seem to work because individuals buy into the idea of democracy, autonomy and social justice through realising practical lived experiences and projects and break challenges into modules that participants can work on (Benkler \& Nissenbaum 2006).

Amateur innovators increasingly become able to manufacture their ideas through smallscale, decentralised manufacturing processes, rather than being dismissed by mass manufacturing (processes that can be compared through the rise of the internet and social media sites, for example, YouTube, Flickr, and Wikipedia, encouraging an increased interest in amateur production and consumption (Anderson 2012)). Such peer production and open source hardware developments are supported through the organisation of events (such as MakerFaires), the development of knowledge sharing websites (and organisations), and the overall political and social aspirations of makers: to democratise manufacturing and innovations process (such as Open Source Ecology).

Despite such efforts, Benkler and Nissenbaum (2006) have argued that there might be a need for policymakers to actively try to support these activities and move beyond their belief that market production from incumbent companies are the main and often only location for economic growth and innovation. Such incumbent companies (grounded in rent-seeking behaviour) might regard peer production activities as a form of competition and therefore try to resist them, rather than build collaborations. For instance, commonsbased peer production and open source hardware and software ideas have problematised

36 Some open source licenses exist, for example, Creative Commons Attribution ShareAlike licence. 
the need for intellectual property rights, something that incumbent companies rely on for their competitiveness. Similar to the developments in the music and film industry, objects could potentially be scanned and endless digital copies produced to be printed anywhere in the world, generating issues of copyright and ownership (Birtchnell \& Urry 2012). ${ }^{37}$ Currently, the source of online, open source design and blueprints available to download is steadily growing, where people freely provide their design files for others to download, alter and print them. Nevertheless, some authors have suggested that the time to freely share files might be limited, considering that digital fabrication technologies create several challenges with respect to trademark law, consumer safety, and copyright. Regulatory bodies might catch up with some of the workshop activities (Morozov 2014).

\section{Reflections on the literature}

Currently there seems to be little reflection on the term democratic and how different democratisations of innovation and manufacturing plays out in daily practices within workshops, considering that this is a major theme in the literature and aim within some workshops. Research needs to, for instance, examine in greater depth: who is represented in workshops and is able to participate, what are the principles for collective decisionmaking, and what is the basis for legitimacy, accountability and authority in current decisions in order to say something meaningful about democratisation processes within community-based digital fabrication workshops.

Moreover, research needs to build on Söderberg's (2013) work that does not only explore the collaborative aspects of community-based digital fabrication but also examines possible tensions that might arise (in his case within the RepRap community - see earlier discussions). In particular, hybrid models (at the interconnections between commercial and non-market activities) with workshops can cause tensions that question principles of openness and reciprocity and therefore problematise the building of trust within these communities. Although workshop participants might aspire to create spaces that are inclusive, and work towards democratic and open-source principles, the achievement of these ambitions is not always a straightforward process and not a given.

As already mentioned above, such open source and democratising innovation ideas are frequently linked to notions of personal manufacturing and mass customisation - the debates of these notions are the topic of the next section.

\subsubsection{Personal manufacturing and mass customisation}

Community-based digital fabrication workshops have been termed to be early forms of personal manufacturing (i.e. the first steps to move these technologies into people's home or to create infrastructure for decentralised manufacturing) (Petschow et al. 2014). These workshops provide fabrication technologies equivalent to industrial machines, just cheaper, easier to use and smaller, until they are inexpensive and reliable enough to move into

\footnotetext{
${ }^{37}$ New business models are therefore instead based on the provision of services cf. ownership of products and knowledge. For instance, in the context of digital fabrication such services might be based on helping people to make things, providing repair services, etc.
} 
homes with a possible profound impact on how people design, make, transport, and consume physical objects (Lipson \& Kurman 2013).

Personal manufacturing processes are argued to go hand-in-hand with a notable shift in consumer behaviour, where people are able to tailor products to their particular needs in order to create individualised experiences (i.e. mass customisation) (Ree 2011). Such consumer-orientated customisations already exist through producer-driven efforts (such as allowing customers product alteration towards the end of the production phase or creating high-end individualised pieces). Digital fabrication technologies (used at home or within a workshop) take mass customisation one-step further. Consumers become prosumers (Toffler et al. 1981; Campbell 2005) because they actively hack, manufacture, make, and tinker with things to create their own, blurring the boundaries between expert and amateur maker (see for example, Atkinson 2006; Kuznetsov \& Paulos 2010). Here, production and consumption processes are clearly interconnected with each other. Some authors have argued that these novel processes possibly influence 'the value of things, communal life, or even whole economies' (Walter-Herrmann \& Büching 2013, p.13).

In particular, FabLabs have been said to advocate 'concepts of reducing the uneven distribution between the few producers and the many consumers or at least herald a future that links itself to the pre-industrial past' (Walter-Herrmann \& Büching 2013, p.13). Rather than having to wait for large-scale companies to integrate peoples' design ideas into their product range, people can print out their design in a small batch and sell it on specialised platforms. Personal manufacturing is said to revive past manufacturing capabilities and creative endeavours within Europe and America, diminishing their reliance on Asian manufacturing centres. Birtchnell ad Urry $(2012$, p.18) have discussed this in more depth stating that the possibility of personal manufacturing disrupting existing global supply systems is due to a number of current elements: political interest in 'homeland' security and manufacturing jobs, growth and resilience; interests in resource security, scarcity and efficiencies'. ${ }^{38}$

Decentralised manufacturing is seen to have numerous advantages over centralised mass production processes: 1) product transportation routes are shorter and therefore lower in cost; 2) the design of products allows for diversity and is more likely to address local needs; 3) production processes (and the use of materials) can potentially be more transparent, ethical and democratic; 4) the required investment and risks can be smaller, in particular, when considering that such production processes can be potentially adapted more quickly when disruptions occur; and 5) it can enable citizen empowerment (Sylvester \& Doering 2013; Schor 2010). This is not to say that centralised mass production processes do not have their advantages (such as possibility to easily optimise, regulate and cheapen production processes) but as argued by Schumacher (1973, p.126) such processes are 'inherently violent, ecological damaging, self-defeating in terms of non-renewable resources and stultifying for the human person'.

\footnotetext{
38 More generally, it might be argued that novel political economic structures in innovation, are considered to have by virtue disruptive influences, and therefore are able to temporarily open up opportunities for more subordinate interests.
} 
A link to the pre-industrial past is considered to be a move towards people designing/making/producing their own objects rather than relying on mass-produced consumer goods. Such changes in manufacturing are sometimes linked to 'a rising of maker culture' (for example, Kuznetsov \& Paulos 2010) i.e. a 'crafting, making, or DIY response to mass culture' (Walter-herrmann \& Büching 2013, p.14). Bueching (2013) has argued that people become more independent in this mode of personalised and decentralised production, creating novel connections between 'makers' and 'industrial production professionals'. Similarly, Illich (1973) wanted to 'retool' society, so that 'traditional politics, with its penchant for endless talk, becomes unnecessary' (Morozov 2014, p.8) - a citizen empowerment through the use of tools (Cooley 1987; Smith 2014; Bookchin 1967).

The concept of a maker culture is not a new one. Some DIY activities arose because of a lack of material resources and lack of capital (for example, depicted in the rationing 'Make, mend or spend?' slogan during the Second World War). In the 60s and 70s, a maker culture movement emerged in Europe and US with the aim to make political and institutional processes more participatory. These aims were meant to critique existing production processes and the global economy (and were frequently associated with a ecological perspective) (Katterfeldt et al. 2013; Smith, 2005). Similarly, the DIY culture in the 90s encouraged an ethics of self-sufficiency, which was closely related to the Punk culture and anti-consumerist ideas (for a more detailed historical analysis of DIY, its link to democracy and classifications of DIY, see (Atkinson 2006)).

Nowadays, the revival of maker culture ideas is comparably connected to a discomfort with today's consumer society. Such discomfort is also considered to be an opposition to the current assumption that the consumer is mainly passive (i.e. 'shift from a sit-back-and-betold culture' (Gauntlett 2013, p.245)). The common belief sometimes exists that if a person knows how a product is made and designed and who made it, they will create a closer connection with it and keep it for longer. Such belief is part of a counter reaction to what is considered to be alienation between today's large-scale and global manufacturing processes and the use of products since the industrial revolution.

For others the rational towards making is connected to political and social activism, which is about encouraging people to understand and reflect upon the technological and institutional infrastructures that 'rule' their life (see for example, Cooley 1987; Smith 2014). For the people involved in such making activities, it is not only about creating countercultures and participating in social activism but also often about the love of making things and solving problems, being engaged 'with the physical and sensual qualities of the material world in a way that ultimately becomes more important than the artifacts that they produce' (Jackson 2010, p.22).

Some actors have claimed that nowadays community-based workshops go beyond 'Do It Yourself' and towards 'Do it With Others' activities (McCue 2012; Sylvester \& Doering 2013), a more collaborative process. As stated by Dougherty (2012, p.11),

'Today's makers enjoy a level of interconnectedness that has helped to build a movement out of what in the past would have been simply a series of microcommunities defined by a particular hobby or activity.' 
Because of the community-based digital fabrication workshops efforts' to combine traditional craft activities with more novel digital technologies, they have frequently been associated with maker cultures (such as making reference to the MAKE Magazine, set up by O'Reilly in 2005) (Katterfeldt et al. 2013). Workshop members consists of 'enthusiasts', 'hackers', 'modders', 'hobbyists', and 'amateurs' (Kuznetsov \& Paulos 2010), who all use digital technologies to make things.

\section{Reflections on the literature}

Considering the above literature, the idea of citizen empowerment through providing tools to people to encourage making process is interesting, in particular when framing it as political and social activism. Here, community-based digital fabrication workshops are framed to be spaces where people can come together to not only debate but also act collectively to pursue political and social goals and to materialise their ideas into physical artefacts, infrastructures, and social institutions. The role of objects in public involvement for political participation has been acknowledged by Marres (2012), but it seems that workshops might take this idea one step further through highlighting the role of making and the materialisation of objects. Nevertheless, coming to the conclusion that the revival of the maker culture (including personal manufacturing) is a way of re-connecting people with the material world in a meaningful manner is questionable. Drawing upon traditions in the study of material culture, Miller (2001) has suggested that consumption is often part of complex practices and grounded in numerous contradictions, as people engage in a struggle to create relationships with things and people. Miller (2001) has advocated conducting research that explores these contradictions and complexities. How people within workshops relate to objects and other people, the things that they make, and the technologies they use to make them becomes an empirical question.

For instance, the use of traditional making methods in combination with digital fabrication technologies is debated within community-based digital fabrication workshops. On the one hand, arguments are being made that digital technologies aid the process of opening up the making culture to the wider public, as no longer traditional crafting skills are needed to create unique and complex pieces - and in the process democratise manufacturing. On the other hand, others argue that some ideas of 'learning, and knowledge which come not before or after but within the practice of making' (Gauntlett 2013, p.25) might be lost in the turn to digital technologies. ${ }^{39}$ Debates in the literature about how digital fabrication technologies and workshops might influence issues of skill and creativity are examined in the next section.

\subsubsection{New conceptions of labour, skill and creativity}

The boundaries of digital and physical production and associated craft and manufacturing processes have become increasingly blurred through the use of digital fabrication technologies. Debates around craftsmanship (i.e. tensions between traditional craft and digitally mediated practices) and skilled labour (i.e. critiquing the automation of labour)

39 Parallels to the Art and Crafts Movement (see Gauntlett 2013). 
have started to arise within workshops and the wider maker movement. Such debates are accompanied by questions such as, 'what different forms of 'work' are required to make physical things through digital means, whether that work is skilled or unskilled, and what forms of value is created and exchanged' (Ree 2011, p.18).

Within some of these debates, several authors and practitioners consider digital fabrication technologies to be substituting the skilled handwork of a craftsman, and with it a crucial element of authenticity (Ree 2011). Rather than experimenting with potential object outcomes whilst trying to shape them physically, the designer creates a digital representation of the object that can be manipulated virtually, almost independent of the materials, and then will be cut or built up through an automated machine, arguably isolating learning through hand making processes and losing the traces of the craftsman's hand. As a response to such arguments, Ree $(2011$, p.71) has claimed that although such tools turn much of the 'in-situ effort of materialisation over to a machine, the machine itself is a manifestation of knowledge, skills and labour involved in its design, manufacture and maintenance'. Moreover, he has tried to argue that there is an element of improvisation and experimentation within the digital fabrication making process. Once the object is created it can be held and studied and therefore altered (often there is the need to finish off the digitally fabricated objects through handwork).

Some have argued that objects are not produced through the owning and employing of certain technologies but through the process of making them (in addition to digital technologies, one might look for a creative analogy at the use of SLR cameras and the Adobe Photoshop programme) (Ree 2011; Burns et al. 2012). Several studies have shown that numerous handicraft and digital skills are required to use digital fabrication tools (Ree 2011). Creating an object from an idea to a digital drawing to the finished thing is not a straightforward process. For example, conducting a creative workshop with participants who had no knowledge of 3D modelling software, Ree (2011) has found that most of them struggled to create a digital file to be printed on a 3D printer. After the design files have been created, an appropriate material needs to be chosen, then the parts need to be assembled and finished which requires several handicraft skills. Still, the absence of any interactions with modelling materials during the design process felt alien to participants, for them "'atoms", as it turned out, did not magically replace "bits"' (Ree 2011, p.38). The workshop participants concluded that in order to print out an object a significant amount of 'skilful human authorship' is required, considering that '3D printers do not make things; people make things' (Ree 2011, p.69). ${ }^{40}$

Over the past few years, community-based digital fabrication workshops have organised training courses and developed open source software that is meant to ease their use. Such activities emphasise the skill required to make objects with digital fabrication technologies and the potential for anyone to learn how to use them (supporting the idea that there is no longer the need for an expert craftsman to make everything). Considering the above outlined debates, it becomes apparent that whether digital fabrication technologies deskill

40 The accessibility of the digital design software in terms of its usability and price can be the first difficulty along the way of creating an object. Commercial software can be expensive and therefore inaccessible to some people whereas open source software can be harder to learn (further, the shareability and adaptability of files between open source and commercial software can be difficult) (DYVIK 2013). 
or reskill people is highly debated in the literature. On the one hand, these technologies are said to encourage passive consumers to engage in creative making process in their spare time without having to pick up years of craft learning - reskilling, whilst on the other, they are said to automate making processes previously requiring craft skill - deskilling.

Drawing on Gershenfeld (2005), Ree (2011, p.92) has claimed that these tools help to 'reverse both the devaluing of artisanship rationalised during the Renaissance as well as the division of labour and 'deskilling" entrenched in the Industrial Revolution'. Further, digital technologies are used to record traditional craft skills to produce learning tools and keep these skills alive (Wood \& Rust 2003; Wood et al. 2009). It seems that relationships between skill/deskill and traditional hand tools/digital fabrication technologies are complex and transform the skill mixes and forms of creativity involved. Such relationships are also apparent in discussions about the technical developments of the open source RepRap 3D printer. Tensions can arise when participants try to create user-friendlier printers that remove some of the entry requirements in using the technology because some of the others might regard such moves, as deskilling the user. Such discussion touches upon the technical, political, economical and social aspirations of the RepRap community that can create several tensions within it, as played out in the technical developments of the machine.

Söderberg $(2013$, p.133) (drawing on Harvey (1982)) has argued that rather than considering 'deskilling in an absolute sense', it is important to consider 'how skill/deskilling plays into power relations... at a given, historical moment', something that these debates have often overlooked. For instance, Söderberg (2013), (drawing on Noble (1984)) has pointed out that when examining the early introduction of digital fabrication technologies (such as computer numerical control (CNC) machinery) power relations within the de-skilling debate become apparent. At the time, factory managers aspired to own a 'fully-automated factory without workers' as way of decreasing the power of existing unions, through the deskilling of existing workers (Söderberg 2013, p.126). Nevertheless, whilst the deskilling of labour was apparent, it did not occur in an absolute sense because through the introduction of CNC machines power was transferred from the skilled factory worker to the computer programmer (who from now onwards controlled the machines). Bringing the notion of power to the deskilling debates, helps to identify 'the recompositions of the labour process and the transient formations of professional identities' (Söderberg 2013, p.126). The skill/deskill debates therefore need to include power relations within discussion and not consider skill as an absolute.

Although today's community-based digital fabrication activities work outside the market bound relations and (within that follow certain political and social aspirations), considering the deskilling debate in relation to issues of power might still be relevant now and within this area of enquiry (as pointed out by Söderberg (2013)). Such reflections become particularly important when considering that communities' efforts have been 'used to procure ideas and innovations for start-up firms and venture capitalists' and framed as being 'free labour in the cultural sector' (Söderberg 2013, p.135; Scholz 2013). Community efforts have increasingly been incorporated into market relations. The question whether to develop more user-friendly machines (also considered as deskilling) to open up activities to a wider audience can create tensions and undermines some community member's political aspirations and social goals. As argued by Söderberg (2013, p.134), 
'What is at stake, in other words, is the ability of the hobbyist community to assert itself and its political vision in a field increasingly dominated by commercial interests. The hobbyists pursue automation with as much zeal as the blue-collar workers fought against it. In both instances, tools and skill are central to preserving the 'functional autonomy' of the collective vis-à-vis an external, hostile force.'

Similarly, Morozov (2014) has pointed to the increasing inter-relationship between marketbased activities and some community-based digital fabrication workshops. For example, the American Department of Defence and the Chinese government are amongst a few actors, who have actively, financially supported some workshop activities. Whilst activities are boosted with the resources provided by these agencies, part of their autonomy and political aspirations can be lost along the way. Community digital fabrication would not be the first example. For instance, the development of the first personal computer started out as a political project (see for example the Homebrew Computer Club). The aims was to 'undermine institutions and allow citizens to share information and organise' but such ambitions were side-tracked once market actors became interested in these technologies and the rhetoric changed to it being a 'project of self-reliance and personal empowerment' (Morozov 2014, p.8; Turner 2010).

\section{Reflections on the literature}

Ideas surrounding automation, authenticity, labour and craft practices seem to be highly debated within the literature. In practice, they seem to transform the notion of skill and creativity into different mixes of skill/deskill and reskill and forms of creativeness. Depending on the authors framing of digital fabrication technologies, they either play a role in deskilling or reskilling people. Bringing notions of power into the discussion seems to be extremely helpful to move away from such dichotomies and make visible the different mixes of skill and forms of creativity and shifting relationships, as they are no longer considered to be as absolute (Söderberg 2013).

Moreover, these discussions touch upon notions of social inclusion: How easy is it to use these technologies? Just how credible is it to expect anyone to make (almost) anything? More user-friendly technolgies might open up community based activities to a wider audience, considering that current membership seems to be reflected in small portion of society: 'the typical hackerspace member is a $27-31$ (29\%) years old male (90\%) with college level or higher education, committed to one hackerspace' (Moilanen 2011, p.8). Nevertheless as outlined by Söderberg (2013), such efforts sometimes undermine community member's activities that reflect wider social goals and political aspirations. Widening the access to digital technologies might make these workshops more socially inclusive but potentially diminish other political ambitions. Although this is a valid argument, not all workshops are politically focused. Opening up workshops to a wider public might bring in new (political) issues and make them more diverse. The point is that in both instances characteristics of the workshop could change, which existing members might not welcome. 
Drawing on Bookchin (1978), Morozov (2014, p.9) has emphasised that an "'access-to-tools" mentality' and aim to get 'more technology into everyone's hands' is not enough to bring about political and social ambitions, 'without taking a close look at the political and social structures in which they are embedded'. Researchers who examine workshops' attempts to become more socially inclusive whilst keeping the social and political ambitions need to consider some possible tensions that might arise between workshop members' ambitions and existing social and political structures. The next section looks at political and social debates within workshops as portrayed within the current literature in more depth.

\subsubsection{Workshops as a novel cultural, political, and social movement?}

Gauntlett (2013, p.233) has claimed that the idea of making and sharing is already a political one'. Although some of workshop members might not pursue political goals, or even see themselves performing political acts, Gauntlett $(2013$, p.233) has argued that the concept and realisation of community-based digital fabrication workshops already 'encompass critiques of the capitalist relations of production, the distribution of power over technology, of excessive affluence, of global division of labour, and so on... and dovetails with political visions of... local production and of shifting the division between production and consumption'. 'As Söderberg (2011) has demonstrated, political convictions of a user community can be often overlooked enabler of technological creativity' (Maxigas 2012, p.3).

To regard the activities of community-based digital fabrication workshops as political can be debated (and even what they mean by political, for example, what forms of politics are ascribed to the workshops), some of the workshops have originated from 'political' movements and explicitly frame their activities around social and political goals. For instance, Maxigas (2012) has differentiated between two different types of workshops i.e. Hacklabs and Hackerspaces that share the same cultural heritage but have different historical and political origins. ${ }^{41}$ According to Maxigas (2012), Hacklabs originated out of a broader anarchist/autonomous movement and are often based in community media labs and squatted social centres ${ }^{42}$, meaning that these communities have developed an overtly political and ideological orientation. On the other side, most Hackerspaces do not define themselves as being driven by political ambitions but rather focus on advancing innovations through digital tools for social and economic goals. They have often rented spaces and can sometimes be linked to public institutions (such as universities).

Such diverging aspirations have impacted on how and what type of technological projects have been pursued and the running and agreed upon practices within workshops. For instance, Maxigas (2012) has argued that 'since Hacklabs are more integral to a wider

\footnotetext{
41 Within the community, there has been recent shift towards developing more collaborative efforts to share information and encourage discussions about its possible future development (Moilanen 2011; Maxigas 2012). Maxigas (2012) has argued that such a shift might provide external observers with the impression that Hackerspaces (he defines Hackerspaces to also include FabLabs, MediaLabs, etc.) derive from a 'single trajectory', which for him is not the case.

42 Media activism (including pirate radio practices, electronic art, and pirate television broadcasts sometimes grounded in the alterglobisation movement) and 'the reappropriation of physical spaces' i.e. squatting have their own historical trajectories but are closely linked to the Hacklabs ideas and spaces (for more information see (Maxigas 2012)). Similarly, ideas from the hacker subculture (such as the Chaos Computer Club in Europe) and free software movement were linked to the labs. The first Hacklabs were established between 1995-2005, mainly in the South Europe. A website documenting the activities of the labs was also set up but it has been taking off the internet since 2006 (partly replaced by Hackerspace website).
} 
political movement, non-technological aspects play a bigger role in how they [labs] are run'. Issues, including disability access and gender relations in labs, are therefore regularly discussed within Hacklabs to create policies concerned with non-discrimination whereas, Hackerspaces regard these topics as less of a concern. Although Hacklabs regularly debate these issues, some labs have made little practical progress in realising such common beliefs.

Similarly, Söderberg (2013) has examined the difficulties of keeping in mind wider political aspirations when specifying technical concepts of possible hardware outcomes. He illustrates such challenges through the development of the Rep-Rap 3D printer. At first, the Rep-Rap community had a keen interest to develop a self-replicating 3D printer and therefore following certain political-economical aspirations. Such aspirations regularly get challenged when making certain design/engineering choices, considering that they are loaded with ideological significance. For instance, 'on the one hand, the use of more advanced components increases the accuracy of prints. When the printing quality is improved, better parts can be made for derivative machines. On the other hand, the chance of printing greater percentages of the parts of the machine decreases the more advanced those components are' (Söderberg 2013, p.129). Instead of mainly following original aspirations for autonomy, self-replication, and accessibility i.e. printing greater percentages of the parts by the machine itself, technical solutions are often pursued that aid the diffusion of the technology, rather than the community's political interests.

Söderberg (2013, p.130) has therefore argued that some projects derived from these workshops set 'themselves the task of building an alternative infrastructure, only to be pulled in by the commercial logic that they sought to undo'. Considering such challenges of pursuing political aspirations whilst at the same time encouraging the diffusing of workshop ideas, technologies and outcomes, Maxigas (2012) has warned that the more overtly political aspirations of Hacklabs could be viewed as 'activist' and therefore be dismissed by the wider public, keeping the ideas to a limited group of people. On the other hand, a lack of more explicit ideology within Hackerspaces might lead to wider diffusion of spaces but also 'to the reproduction of dominant power structures' rather than providing alternatives.

The lack of coherence between workshops and their diverging historical background, according to Maxigas (2012), has prevented the community to be regarded as a social movement. For him, this might be their political potential, as they are free from such conventions and exist at the intersection of being a 'geeky workshop paradise' (Grenzfurthner \& Schneider 2009) and 'genuinely contestant spaces that have a wide impact' (Maxigas 2012, p.8). Still, the political directions and intentions of such workshops (and whether they exist in the first instance) are unclear (Grenzfurthner \& Schneider 2009). The importance of developing ideological and theoretical debates (in the realm of economics and politics) has also been highlighted by Prug (2013) when examining peer-topeer practices. He has argued that such practices can become dependent on those same structures unless actors make these workshop practices an object of debate within the context of existing societal, political and economic structures.

In contrast to Maxigas (2012), studying FabLabs as a type of social movement, WalterHerrmann (2013) has argued that the FabLab network could be regarded as a movement. For him, firstly, the network creates 'social movement repertoires' such as conferences, 
workshops and fairs, secondly, makes 'collective claims' (Tilly 2005, p.3) that can be viewed by the public such as the outline of the Fab Charter, and finally, tries to build 'collective representations' (Tilly 2005, p.4) such as developing common values and novel goals and purposes (Walter-Herrmann 2013). However, what differs between this movement and social movements in the past is the way they can demonstrate their disagreement with existing structures and institutions, making use of social media tools (such as Twitter Hashtags) to spread discussions and expressing movement ideas in material outcomes/processes through exhibitions (Walter-Herrmann 2013).

\section{Reflections on the literature}

As outlined in the literature, the political ambitions of workshop members often are interlinked with the content of their projects and their technological creativity - even though some of these links are not explicitly expressed. Nevertheless, such ambitions and creative efforts are frequently pulled into commercial logics and have to work within existing structures that some of these workshop members want to actively change. Consequently, some of the debates in the literature stress the need for the workshop community to be reflective about their activities and how they sit within wider social and political discussion. Through these reflections members are able to shape these debates rather than being shaped by them.

Whether community-based digital fabrication workshops create a social movement might be a secondary issue for now. What might be more interesting to point out from the literature that in comparison to past social movements, workshop members have access and build different tools to organise themselves and their efforts (sometimes having an active interactions online and face-to-face), creating a connected global community. Moreover, as already outlined in section 6.1.2, it seems that workshop members practice their political activism through different means than, for instance, lobbying - and rather through the materialisations of alternative production and consumption technologies and practices. $^{43}$

Currently, claims are being made within the literature about community-based digital fabrication workshops transforming practices of design, innovation, production and consumption, whilst describing positive impacts on the environment and social goals (Olson 2013). These claims and debates are outlined in the next section.

\subsubsection{Debates around sustainability ${ }^{44}$ in the context of GDF}

Some community-based digital fabrication workshops aim to enable design for recycling and re-manufacturing, feed user-led prototypes into sustainable local enterprises, and realise sustainable design projects. They might even reinforce virtues relevant to post-consumption societies through peer-production, the sharing economy, and collaborative consumption (Thorpe, 2012). However, some studies have also suggested that developments of digital

\footnotetext{
43 Moreover, this might be a different kind of social movement in the sense that it does not demand rights from the state or social institutions (such as environmentalism), nor does it seek to express and exert an identify and recognition of a culture (such as oppressed groups).

${ }^{44}$ We follow the World Commission on Environment and Development (Brundtland) definition of sustainability and understand it to include issues of social inclusion as well as environmental integrity.
} 
fabrication technologies can lead to a dispersal of production capacity, diminish (resource) scale efficiencies, and intensify consumption through the possibility of endless, customised manufacturing. Although some studies have tried to examine the possible environmental and social impact of digital fabrication technologies (in particular 3D printers), through life cycle assessments of particular technologies (Kreiger \& Pearce 2013; Faludi 2013; Petschow et al. 2014) and scenario building activities (Birtchnell \& Urry 2013) ${ }^{45}$, research that examines sustainability implications for workshops and digital fabrication technologies still are rare (Olson 2013). Some of the discussions and studies surrounding these issues are delineated in more depth below.

Efforts have been put into assessing the environmental impact of digital technologies through comparing the life cycle assessments of several technologies (Faludi 2013) or manufactured items, whilst comparing them to conventional production methods (Kreiger \& Pearce 2013). For instance, Kreiger and Pearce (2013) have tried to quantify the environmental impact of distributed manufacturing using the open source RepRap 3D printer, conducting a life cycle assessment of three plastic product outcomes. ${ }^{46}$ They considered in their 'cradle to cradle' analysis 'the embodied energy emissions from conventional large-scale production in low-labour cost countries and shipping are compared to experimental measurements on a RepRap with and without solar photovoltaic (PV) power fabricating products with acrylonitrile butadiene styrene (ABS) and polylactic acid (PLA)' (2013, pp.1513, 1511). ${ }^{47}$

At the beginning of the paper, Kreiger and Pearce $(2013$, p.1511) have hypothesised that distributed manufacturing with open source 3D printers will potentially reduce the environmental impacts of plastic products, when comparing it to conventional production methods. 3D printing 'allows for the fabrication of extremely complex geometries, customisation, and minimisation of production waste compared to subtractive manufacturing, while maximising material utilisation' (Kreiger \& Pearce 2013, p.1511). Examining the production of three plastic products more closely, conclusively, the preliminary results have shown that 'the cumulative energy demand of manufacturing polymer products can be reduced by $41-64 \%$ and concomitant emission reductions using distributed manufacturing with existing low-cost open source 3D printers when using $<25 \%$ fill PLA' (2013, p. 1511). These results are mainly based on the fact that 3D printers allows for '(1) the ability to adjust the internal fill of a product, (2) the ease of adapting to PV power, and (3) the ability to further reduce environmental impact using improvements in energy efficiency of printing technology and recycling filament' (Kreiger \& Pearce 2013, p.1516).

Although Kreiger and Pearce (2013) are aware of the limitations of their research (see also 2013, p.1517), the results need to further be considered with caution, considering that the

\footnotetext{
45 Several industry bodies have also explored the potential of advocating 3D printing as a 'cleaner manufacturing' possibility - see for example the Atkins Feasibility Study conducted by the Additive Manufacturing Research Group (as referred to by Lipson and Kurman (2013, pp.202-204)).

Work on the topic is also done by academics at the University of Nottingham (see for example: http://www.nottingham.ac.uk/engineering-rg/manufacturing/3dprg/people/christopher.tuck) and the University of Loughborough (such as http://www.lboro.ac.uk/research/amrg/about/facilities.html).

${ }^{46}$ Naef building block, water spout and juicer

${ }^{47}$ An additional study by Pearce et al (2010) examines the potential of open source 3D printers to drive self-directed sustainable development.
} 
recyclability of plastic filaments and improvements to energy efficiency are not necessarily a given to the technological development and also depend on various cultural and social developments. Further, in response to the paper, Faludi (2013) has argued (as part of an O2mailing list discussion) that the results need to be carefully interpreted, considering that the authors: 1) compared dissimilar materials and production methods for some of their three products; 2 ) chose not particularly representative products; 3 ) implied that transportation is one of the major environmental impacts, and 4) assumed in parts that the 3D printers would be run on solar power.

These discussions suggest that analysing the life cycle assessment of 3D printers is not an easy undertaking, in particular, when trying to predict possible technical, social and cultural developments of the technology and deciding on the boundary condition of the study. Olson (2013, p.34) has even argued that 'their [3D printers] ability to revolutionise manufacturing, including environmental and energy benefits, is a long way from being proven'. For him, the variations between 3D printing technologies, methods of adding up substances and use of materials, and predicting the possible technical improvements of the technology (such as increasing the 3D printing speed and the amount of materials printed at a time) are one of the key difficulties to analyse their possible impact on the environment. Further, Olson (2013, p.34) has argued that several questions need to be addressed before conducting any type of analysis: 'What technologies are involved in 3-D printing? How efficient are these technologies in the use of materials and energy? What materials are used and what are the worker exposure and environmental impacts? Does the design of printed object reduce endof-life options? Does more localised production reduce the carbon footprint? And will simplicity and ubiquity cause us to overprint things, just as we do with paper?'

Drawing on a study conducted by Faludi (2013) and his colleagues at the UC Berkeley, Olson (2013) has pointed out that the environmental impact of 3D printers depends more on how they are used, rather than on the type of printer. For life cycle assessments, the usage of printers is difficult to determine because it is highly depended on the user, and their use context, and can vary greatly. Analysing the environmental impact of two different 3D printer technologies and a computer-controlled mill, Faludi's (2013) study has shown that the greatest environmental gain comes from using a small number of printers at high production rates. He has therefore suggested that people should share fewer printers and then utilise them to their maximum capacity.

'3D printing won't be an innately green manufacturing technology unless we actively seek to make it one. If we can tap into 3D printing's unique capabilities and invent greener printing materials, we will reap environmental benefits in the form of shorter supply chains and a new generation of optimised products' (Lipson \& Kurman 2013, p.215).

Furthermore, these studies look at 3D printing in isolation, whereas other literature reviewed above identity a variety of technologies used in community-based digital fabrication workshops' projects, and the culture within workshops (such as members' aims) also influence the relative sustainability of any given digital fabrication activity.

A number of more debated environmental claims (comparing digital fabrication technologies, in particular 3D printers, with conventional manufacturing process) have 
emerged over the last years (Olson 2013). The claims are as follows: 1 ) they produce less waste, through recycling, additive manufacturing, and repair 2) they are more energy efficient, 3) they allow for design optimisations ${ }^{48} 4$ ) they reduce energy use and emissions associated with the transport of products, 5) they facilitate a decrease in the consumption of things, and 6) they increase the longevity of a product's life (Olson 2013). These statements are currently being disputed within the literature on digital fabrication and 3D printing. For instance, although some 3D printing technologies are more energy-efficient than more conventional manufacturing technologies, some printers use up to ' 80 times more energy than others [manufacturing methods]' (Olson 2013, p.36). So the energy efficiency of printers is determined by their technology. In addition, the production volume and material used can play an important role in determining the energy-efficiency of the printing process in comparison to more conventional manufacturing (such as injection moulding).

Transport reduction (or a potential increase) is a further topic that is highly disputed in the literature. For instance, Birtchnell and Urry (2012) have speculated that transportation (in particular freight) impacts on the environment could be potentially reduced through manufacturing objects locally where they are needed, rather than half way across the world. Within their scenarios, digital design files would travel around the globe and the product would actually be produced locally in a workshop, shop or at home (i.e. localised manufacturing).$^{49}$ In contrast, Olson (2013) has argued that calculating the impacts of digital fabrication tools on transportation is not a straightforward undertaking. When analysing the transportation impacts it is also important to consider that digital fabrication technologies need feedstock, raw and building materials to create these objects that might still have to travel around the globe. Such materials currently mainly rely on oil (such as powders and plastics). Moreover, it is difficult to speculate whether large shipments of products and materials outweigh the environmental impacts of many small ones between homes, stores and raw material sites, in addition to the shipments of digital fabrication technologies to their place of production.

The above outlined debates seem to imply that the environmental impacts of digital fabrication technologies and associated infrastructures and practices will depend on the technical developments of digital fabrication technologies, future infrastructures of manufacturing products, cultures of consumption and production, relations with the state, markets and regulations, and supply and demand side transportation systems. In addition to such developments (and maybe even more importantly), it is important to consider how products and printers will be used and taken in up in everyday work and home activities. Their use in homes, shops and workshops even more so determines in how far printing processes create waste, possibilities and uptake of recycling, and how many products people might own and for how long they will keep them.

\footnotetext{
48 For example, the SAVINGS (Sustainable product development via design optimization and AdditiVe manufacturING) project aims to create more sustainable products using 3D printing. It was established in 2009 and has been funded by the UK's Technology Strategy Board. (Barnatt 2013, p.161)

${ }^{49}$ Such changes within transportation can also have an impact on the storage of products. If products will be produced locally there would be less of a need for huge and temporary storage facilities that need to be build, maintained and heated (Huang et al. 2012; Lipson \& Kurman 2013).
} 
For example, some studies have shown that 3D printing technologies (in particular, ones that extrude plastics through heated nozzles) can create objects, whilst producing hardly any waste. Nevertheless, such examinations frequently seem to ignore that some objects require support materials to be printed, which gets cut and filed away (or in some processes dissolved away with chemicals) at the end of the manufacturing process and that people might print out several versions of the same object before they are satisfied with it. In both processes, waste would be produced that is difficult to predict. Similarly with recycling processes, although, attempts are being made to easily recycle waste materials or unwanted products (through developing recycling machines and services - see for example, Filabot and RecycleBot projects) (Lassiter 2013) or the development of biodegradable, plantbased printing materials, the increase and uptake of these services and products is not necessarily built into the technologies. Providing an infrastructure and technologies for recycling might therefore not be enough to encourage people to take them up. Social, economic and cultural conditions will also influence whether people wish to take up technologies for recycling, and the kinds of practices that might emerge through introduce these technologies. Moreover, printed objects increasingly become more complex, mixing multiple materials, which decreases the possibility for recycling items (Olson 2013).

Some claims about how digital fabrication tools could potentially change current 'unsustainable' consumption patterns, go even further than considering waste and recycling implications. Some academics and activists (see for example Schor 2010) have linked current developments of digital fabrications technologies and community-based workshops to the rise of the maker culture (Hatch 2013), where people start to question their relationship to current consumption patterns and start to repair, up-cycle, and fix their things rather than throw them away (in particular in the light of the Great Recession) (Ree 2011; Nierling 2012). For instance, Gauntlett $(2013$, pp.10, 219) has suggested,

'But it is the fact that people have made a choice - to make something themselves rather than just consume what's given by the big suppliers - that is significant. Amplified slightly, it leads to a whole new way of looking at things, and potentially to a real political shift in how we deal with the world.'

'Making things, as examples of future creative diversity, in the here and now, offers a powerful and tangible form of inspiration to others - and challenges the apparent inevitability of the present'.

As part of this rhetoric, some authors have argued that consumers through the uptake of digital fabrication technologies will regularly search for authenticity: wanting to know where products come from, who makes them and out of what materials and therefore start to strive to live more sustainable and self-sufficient lifestyles. Moreover, customers would be able to customise products (and in the process become prosumers rather than 'passive' consumers) to their particular needs, potentially creating a closer bond to the products they make, keep it for longer, are more likely to repair it (some community-based digital fabrication workshops have organised repair nights ${ }^{50}$ ) and therefore require less things.

\footnotetext{
50 Repair nights are not a new phenomena and are part of a wider and global 'repair movement', consisting of repair cafes and fix it clinics (see for example (Rosner 2013, pp.55, 73) considering them as example of 'politics-in-themaking').
} 
Such efforts are said to have the potential to break down exiting centralised massconsumption and mass-production systems and in the process allow for 'material forms of civic engagement' (Ree 2011, p.88).

Currently these claims are highly speculative. They also presume that people are free to make individual choices over lifestyles in which they can take up certain technologies and practices, rather than considering the structures that condition practices and lifestyles. Past technological developments (such as low-cost laser printer did not lead to the paperless office) have promised similar impacts on the way we live and relate to our products but they never materialised and in some cases actually brought up more unexpected practices. Engaging with 3D printing processes during a creative workshop, in Ree's (2011) study, participants were wondering whether the use of a 3D printer 'reframes existing notions of work involved in making things, and the potential trivialisation of both design and objects that might result' into encouraging new consumption patterns but ones that have an even greater negative impact on the environment. In addition to developing the technical and infrastructural aspects of digital fabrication, it might be key to examine and facilitate accompanying home, work and leisure practices associated with these technologies (as suggested by Birtchnell \& Urry 2013).

Digital fabrication technologies are often idealised by advocates who contribute to a rhetoric surrounding their potential societal impacts but have actually never tried to use these technologies (Ree 2011).

'The hype has inflated expectations to a fever pitch, ignoring some uncomfortable realities and guaranteeing disappointment... Just as with music, writing, and programming, most prefer to consume the work of others'. (Levinson 2013, p. 45)

Drawing on Bell and Dourish's (2007) work on ubiquitous computing, Ree (2011) goes on to say that such rhetoric frequently romanticises the future impacts of technologies as if they are 'just around the corner'. Still, the rhetoric might have an important role to play in the development of digital technologies and its impacts on society. Reading the work of Woodward (2009), Ree (2011) has suggested that 'the manner in which the cumulative effect of such rhetoric amounts to a body of cultural narrative that frames desktop 3D printers and 3D printed objects' is an important issue to study.

'The rhetoric informs the manner in which 3D printing is used, interpreted, integrated and altered in the creation of meaningful, resonant stories and messages are created around these engagements that gradually become enmeshed and communicated through the cultural fabric - a body of cultural mythology (Barthes 1973).' (Ree 2011, p.65)

For Bell and Dourish (2007), it is key to study existing interactions with these technologies and the infrastructures that they create. Such interactions embody a 'messiness' where 'we see that infrastructures are continually visible and must be consciously attended to in the course of everyday encounters' (2007, p.139).

Reflections on the literature 
Currently claims seem to be highly speculative about the possible influence of grassroots digital fabrication on issues of sustainability. Considering the above outlined limitations of life cycle assessment studies (fraught with difficulties and disputes) ${ }^{51}$ within this area, dedicating research resources to highly uncertain energy quantification might be inappropriate. Generating insights into the contending narratives influential in digital fabrication developments, and how people are experimenting with sustainable, low energy possibilities might be a more fruitful line of inquiry. Studying the cultures of production and consumption cultivated in workshops and other sites of take up seem to be key, and therefore how technologies are valued and used. Co-producing investigations with participants would make community-based digital fabrication workshops even more relevant sites of research, since this is where (certain) people come together and can discuss these issues in a relatively familiar an informed way.

When studying workshops in relation to sustainability issues it might be important to consider, what Robben (2013; taken from Marx 1867) has outlined in the statements,

'Are these activists the conscious architects of their products? Or do they act like inferior animals, which unconsciously build useless things? Perhaps, a more realistic view would be that they are both: sometimes taking up the role of an architect, sometimes the role of the bee.'

Considering this statement, before asking which possibilities workshops present for sustainability, researchers might need to examine in how far these issues currently feature in workshop projects, and if so are members conscious architects or bees? Moreover, it might be interesting to examine how more prevalent issues discussed and addressed in the workshops (such as open source agendas) influence notions of sustainability. Sustainability does not necessarily need to feature within these workshops, but they could still have a profound impact on social and environmental issues. Moreover, analogies to other technologies that promised great changes to society could be drawn to examine the potential social and environmental impacts of grassroots digital fabrication. Some of these analogies are discussed in the next section.

\section{Analogies with other technologies and movements}

Links have been made between open source software and hardware practices. Analogies are drawn between what is emerging in digital fabrication, and what preceded it in software and on-line cultural content. The move is seen from 'bits' to 'atoms'; although Troxler (2013) has argued that software practices cannot be easily translated into the hardware domain. Open source software and hardware practices have got some inherent differences: 1) materials and manufacturing tools can be expensive and therefore are not easily accessible; 2 ) simplifying systems and processes (into modular form - as is typical in free and open software projects) is not a straightforward process in hardware; and 3) the field of hardware is broad (from cups to houses) (Troxler 2013).

\footnotetext{
51 Even wider studies on life cycle assessments (considering other technologies) have shown that such assessments can be fraught with disputes. Some argue that through legitimate tweaking of assumptions within such assessments any case can be made, depending on the overall objective of conducting it (Stirling, 1999).
} 
'The route to the new world of Open Source hardware and distributed manufacturing might be somewhat thornier than in software.' (Troxler 2013, p.183)

Even when considering their differences, the development of infrastructures, practices and designs for open source hardware can be framed similar to the open source software domain as a 'peer-produced common' (Troxler 2013, p.185). It might therefore be possible to argue that similar discussions and issues are apparent within open source software and hardware developments.

For instance, the literature on hacking, cracking, file sharing, free software and open source activities is made up of discussions on 1) the development of democratic governance structures within peer production projects (Dafermos 2012), 2) the tackling of wider social and environmental goals within software communities (such as the 'Social Innovation Camps $^{\text {'52 }}$ and 'Humanitarian Hacking')(Mcquillan 2012) ' $^{53}$, 3) the relationship between face to face and digital interactions within hacking communities and the importance of being networked (Coleman 2010; Haywood 2012), and 4) the politics involved in commercialising and popularising these activities (Söderberg 2010b; Magaudda 2012). Considering that this literature is potentially more mature than the one on open source hardware and community digital fabrication developments, it might be important to draw out some of these discussions to able to reflect upon how they interlink with digital fabrication (whilst remaining alert to the material differences that could affect the ways these issues play out).

For instance, research on the development of governance structure within open source software projects has shown that the move towards more hierarchical/supervisory governance structures is not necessarily a given when organisations/groupings grow in size (Dafermos 2012). Examining the development of the governance structure of the FreeBSD ${ }^{54}$ project, Dafermos (2012) has shown that they went from an informal governance structure to a democratic governance phase which still is 'decentralised and anti-hierarchical: tasks are self-selected by committers as their needs and interests best dictate' (Dafermos 2012, p.9). Such governance structure (termed by Demil and Lecocq (2006) have a 'bazaar governance') partly exist because of the moral values adopted by its members and the hacker community as a whole i.e. hacker ethic (Levy 2001).

Although internal structures are likely to be non-hierarchical and persist over time, commercialisation and popularisation processes of hackers' activities and outcomes frequently seem to put at risk some of their ethical and political ambitions. Examining the 'different responses to the intensified commercialisation of the Czech wireless network community', Söderberg (2011) has shown that political aspirations can be pursued in several ways within these projects and with varying consequences. One project aimed to 'challenge the monopolistic business practices in the Czech Telecom sector... to contribute to a decentralised community network' (Söderberg 2011, p.240) by setting up a start-up firm. On

52 "What happens when you get a bunch of software developers and social innovators together, give them a set of social problems and only 48 hours to solve them? Social Innovation Camps are about finding out." (http://sicamp.org/si-camp-uk/)

53 Other hacker events are: Hackathons, Hacker cons, camps, fests, etc. made famous by the Homebrew Computer club and the 'Foobar' hacker events inspired by 'Open Space Technology' and 'Temporary Autonomous Zones (Haywood 2012).

54 A free open source operating system descended from the Berkley Software Distribution 
the other hand, the founder of one of the other projects was keen not to use market-based instruments to finance their efforts but rather drew on a donation model. For Söderberg (2011, p.241) both projects therefore pursued a difference political strategy,

'While the first strategy looks for possibilities to improve the way a local market works (or at least limit its destructiveness), the latter strategy insists on thinking beyond the market economy as a whole.'

Such strategies do not only impact on the ways people try to finance their projects (i.e. through a start-up form or drawing on a donation model) but also on the technological development of the wireless network (such as forms of maintenance, ease of access, and willingness to share information). The technological design of the network was altered within the process of commercialising and/or growing the network and sometimes 'displaced the political aspirations which had originally been invested by its users' (Söderberg 2011, p.246).

Similarly, Magaudda (2012, p.6) has demonstrated that the usual complexities and specificities belonging to the hacking realm have undergone a process of simplification... as a process of "consumerisation" of hacking practices'. In addition to gaining an increased visibility within popular culture, hacker practices and events have started to be financed by large corporations, trying to boost their overall image, encouraging an increased commercialisation and popularisation of their efforts. Magaudda $(2012$, p.7) has argued that in parts such practices have impacted on consumer attitudes towards their consumer goods, as 'the modification of objects are increasingly integrated into the consumption and circulation of goods' ((Magaudda 2012, p.7) drawing on (Campbell 2005)). Similarly, Haywood $(2012$, p.4) has argued,

'I contend, however, that this 'hacker ethic' has had an influence upon areas beyond computer hacking. This can be seen, I would argue, across a range of interrelated emergent practices including crowd-sourced data, 'the clean web', open-data, open-government, open-education and even democratised activism of the 'Arab Spring', Occupy and Anonymous 'movements. Rather than being purely the result of technological advances then, these practices might be seen as indicative of wider social and cultural changes.'

Such commercialisation and popularisation process do not only influence consumer practices but also impact on how hacking is represented. For instance, law enforcement agencies are able to create a clear distinction 'between users and misusers' of technology within hacking community. Often they distinct hackers into 'users and misusers' without acknowledging that hackers (who are counted as 'misusers') 'innovate precisely in order to overthrow the material practices upon which intellectual property law is founded' (Söderberg 2010a, p.151). Söderberg (2010a, p.172) has argued that such representations of hacker practices risk to characterise the inventiveness of users as chiefly a matter of peaceful deliberation and co-operation... [rather than] caught up in antagonistic conflicts'.

\subsection{Reflections on the literature}


Similar analogies can be drawn between the development and diffusion of personal computers (Walter-Herrmann \& Büching 2013) and current open hardware developments and community-based digital fabrication activities. In particular, the hype and envisioned opportunities of how digital fabrication technologies will potentially have an impact on how people live, work, play, and manufacture draws attention to similar technological promises in the past (such as the paperless office, gender equality through the introduction of the internet, or flexible specialisation). Comparisons could be drawn between past potentially promising technologies and digital fabrication technologies but it might be questionable how much such an investigation would tell people about the future implications of these technologies. What such analogies, however, show is that it is the importance of critically investigating current and possible future possibilities in their social context that is important.

\section{Discussion}

The literature review highlights that excited claims are made about community-based digital fabrication workshops transforming practices of design, innovation, production and consumption. This includes claims for a third industrial revolution and post-consumer sustainable societies. Less evident, however, are social scientific analysis of the practices and governance arrangements actually emerging in workshops and their related networks. What research does exist points to an emerging field of social activity based in and around community-based digital fabrication workshops that is very dynamic and heterogeneous. Even in the case of Fablabs, where workshops follow a charter and derive from a common source, there is considerable diversity.

Considered as a grassroots innovation, this diversity in community-based digital fabrication workshops is not surprising. Whilst ideas for community-based workshops are not entirely new (Smith 2014), the possibilities opened-up by digital social media for networking, collaborating, and social activism is a novel development. To the extent that workshop members are taking advantage of deeper-seated changes in society (be it emerging social movements, new technologies, shifting cultures, or restructuring economies) their development provides an arena for reflection on wider cultural and societal influences than simply cataloguing the objects being made and their techniques of fabrication. Some of the existing research is pointing towards deeper analytical possibilities, but the potential is only glimpsed currently through a wider literature that is more technical, descriptive, or rhetorically orientated. From a grassroots innovation perspective, this suggests that the more transformative aspects rest in the social, cultural and political features, over and above the generation of myriad more specific innovations. To illustrate, a specific up-cycling project, say, is certainly socially innovative, but it is the material cultural explorations that this signifies that point to socially transformative possibilities.

Similarly, the dynamism and heterogeneity in these community-based digital fabrication workshops suggests detailed sustainability assessments will be extremely complex, provisional and ultimately elusive. The literature review has shown that life cycle assessments of specific objects or digital fabrication technologies have been a challenging task, and whose social meaning was uncertain. Some workshop activities try to enable design for recycling and reuse, and encourage the development of renewable technologies. 
They might even address relevant issues that could bring about a post-consumption society (Thorpe, 2012). However, such evidence is sporadic and does not exclude scenarios in which consumption processes could be intensified through, for example, increased personalised manufacturing. As with grassroots innovation so with sustainability, the literature seems to point to the need for a critical analysis into the wider social, cultural and political aspects of workshops' activities and aims.

Analysing such social, cultural and political aspects in order to gain insights into the deeper social science analytical possibilities has implications on the methods used to study these workshops. The activities of community-based digital fabrication workshops are part of a global and multi-sited phenomenon. Activities can happen simultaneously and connectedly at different geographical scales (locally, regionally, nationally and internationally), in various spaces (on-line and off-line) and through different media (such as Skype, internet forums, conferences and Twitter). As pointed out by Haywood (2012, p.2), workshop members are 'highly mobile', making it challenging for researchers to conduct research in this area. The literature review has shown that in the past, researchers have therefore drawn on ethnographic approaches to examine community-based digital fabrication workshops. Although such methods allow for an in-depth investigation, it is difficult to say what a handful of thick descriptions (that in the past have sometimes lacked theoretical analysis) could actually say about the development of such a heterogeneous, global network. Consequently, social science research might be needed that makes use of mixed methods to be able to grasp this multi-sited phenomenon and tries to draw out several theoretical reflections that examine the transformative potential of workshops, and what these imply for critical social issues.

At the outset we suggested that these critical issues could include sustainability, inclusion and creativity (see Smith et al. 2013 for a more in-depth exploration of these issues) as emblematic for wider social concerns. The following section attempts to critically outline some of the key themes derived from the existing literature in relation to these issues, and suggest possible future research areas.

\subsection{Sustainability}

Claims seem to be speculative about the possible influence of community-based digital fabrication workshops on issues of sustainability within the current literature. Similarly, it is still relatively unknown in how far such issues feature in the day-to-day practices and discussions within workshops. Life cycle assessment studies seem to be fraught with difficulties and disputes, often struggling to set the boundary conditions of these assessments, and disregarding possible cultural and social developments. Studies that consider the culture of production and consumption are extremely tentative, envisioning possible future scenarios that rarely ever consider existing debates and practices. Although such existing debates might not relate to sustainability issues, they play a part in shaping future practices that have implications for energy demand (and other sustainability related topics) and therefore are important to study.

Moreover, researchers (who are interested in sustainability) might need to be reflexive about their own interpretations of practitioner activities and aspirations when investigating 
these workshops in order to avoid misinterpreting them or overlooking alternative possibilities in these activities and their transformative potential (beyond the researcher's own normative goals). Rather than going along with the hype that has mainly been shaped by observers and frames workshop activities in relation to wider social and economic goals, researchers need to provide a critical examination that is based on investigating the interrelationship between existing frames and workshop members' practices, projects and discussions. Although most of workshop members' practices might not be framed in relation to environmental and social aims, potential sustainable practices, for instance upcycling, arise in personal projects across workshops. It is the totality of these practices that become interesting for a researcher with research aims relating to the issues of sustainability. Nevertheless, in these instances researchers have to be reflexive and clear that they are making these interpretations, and it is not the workshop members who are expressing them.

\section{Possible future research questions that derive from the literature review}

- How does the notion of sustainability currently feature in workshop practices and debates? How do current debates and practices within workshops relate to sustainability issues? What possible tensions derive from taking up these issues?

- How does the current hype around community-based digital fabrication workshops influence workshop practices on the ground (and visa versa)?

- What type of cultures of production and consumption are cultivated in communitybased digital fabrication workshops? How are technologies valued and used?

\subsection{Inclusion}

Considering recent surveys into workshops as outlined in the literature review, most of the members are technically interested and well educated and therefore represent a particular fraction of society. Some workshops might try to actively increase their membership, such as through outreach programmes to particular social groups, but others are more concerned about the pragmatic and practical side of developing grassroots digital fabrication technologies. Past research into workshops has even shown that the development of such technologies sometimes creates tensions between making these activities more inclusive or generating political, economic and social alternatives (such as open source ideas). Aims and aspirations within workshops are diverse and frequently need to be negotiated and balanced as they can stand in direct conflict with each other.

Moreover, workshop members' efforts are frequently pulled into commercial logics that force members' activities back into existing structures, which sometimes leaves little space to think about ways to be more inclusive. In particular, FabLabs that are located within or financed by host organisation are expected to be self-financing after a certain period of time. Rather than opening their doors to the wider community, some workshops are compelled to increase their income through facilitating commercial activities. Such dynamics do not only question the inclusivity of these workshops but also raise questions about the economic power relations involved in community-based digital fabrication. Aspiring to certain social goals and trying to materialise them within workshop practices and projects does not seem to be a straightforward process and therefore deserves further 
examination. We need to understand better those workshop practices where inclusion works well, and the challenges that make it difficult for workshops to be as open as they might wish.

Possible future research questions that derive from the literature review

- What are the current relations between commercial and non-commercial endeavours within community-based digital fabrication workshops? How do these relations influence members' social, cultural and political ambitions?

- What tensions does the heterogeneity of aims within workshops currently create? What impacts do they have on workshop practices and their wider social and political aims?

\subsection{Creativity}

Within the existing literature some connections are made between community-based digital fabrication workshops and the rise of the maker culture. We have seen how the literature considers the skills required to participate in grassroots digital fabrication, and the training and learning-by-doing available to workshop members. Of course, creativity is a much more complex quality than possessing the skills to make things. Here, there is less evidence in the literature for studies of how workshop participation cultivates creativities. The sharing and adaptation of designs, watching one another's projects develop, being part of a making community; all expose people to ideas and practices that might resonate with their own creative instincts. The relationships between individual and social creativity are ripe for study in these workshops and across the networks that join them together.

Further links are made by advocates between creative workshop members and ideas of citizen empowerment through providing tools to the masses ('a liberation through the act of making'). Traditional crafting skills are no longer needed because easy to use digital fabrication tools are said to democratise making and manufacturing processes. And yet, we find critical investigations into how democracy is practiced and how such efforts might empower people in workshops are rare within the current literature. In addition, research needs to critically examine just how far an 'access-to-tools' agenda is sufficient to democratise innovation processes, particularly if such an agenda does not address the existing political and social structures in which they are embedded.

An 'access to tools' agenda is often associated with visions for people able to create and personalise their own products, or to participate in collective prototyping and development activities, and consequently re-connecting them with the material world in a meaningful manner (connected to a post-consumption society). Arguably, this way of viewing people's consumption practices and relationship to their products is rather simplistic and seems to overlook that consumption is often part of complex everyday practices and grounded in numerous contradictions. Nevertheless, community-based digital fabrication workshops attempt to materialise alternative ways of innovating, manufacturing and consuming that rely on more democratic and inclusive processes that deserve further investigation. And the view that people are inherently creative, and find meaning in making things, is part of a long tradition in radical political philosophy, particularly Marxist ideas about alienation of people 
from the things they produce (Cooley, 1987). In how far such materialisations are enough to address issues like alienation, and wider social and political goals (without actively questioning existing structures in which they are embedded) is important research question to explore.

\section{Possible future research questions that derive from the literature review}

- How do members material capabilities and skills link to their wider social and political ambitions? In how far do people need to become makers (with enhanced technological skills) to be part of the revolution?

- How do members' political and social aspirations influence workshop projects and practices? In how far can the making process be framed as a form of political and social activism?

- How do notions of democratising innovation and manufacturing play out in daily workshop practices?

The literature review has shown that investigating community-based digital fabrication workshops in the light of the excited claims (such as a driver for a post-consumer sustainable societies) being made about them is not a straightforward process. There are several methodological considerations that need to be addressed. Moreover, researchers need to be reflexive about their own interpretations of practitioners' activities (and normative research goals), considering that they can play a role in shaping and representing such activities, and that can feedback into discourses and perform a role in subsequent developments. Such reflexivity becomes particularly important when considering the numerous tensions and conflicts that can arise when workshop members attempt to address a variety of goals with their activities, as highlighted by the existing literature. The negotiations of such tensions across a network of workshops seems to be key when thinking about the transformative potential of these workshops in relation to addressing wider environmental and social issues. But retaining a critical reflexivity is also important for more constructive reasons. It contributes importantly to the conditions for keeping open the plural possibilities for workshops under a variety of social scenarios. The diversity of transformational pathways that workshops could contribute towards should be explored fully, rather than (research) discourse closing down too quickly around particular framings of community workshops.

Please get in touch if you wish to learn more ${ }^{55}$, become involved or like to add, correct and comment on these questions or on the literature review as a whole.

\section{References}

Anderson, C., 2012. Makers: the new industrial revolution, London: Random House Business.

Atkinson, P., 2006. Do It Yourself: Democracy and Design. Journal of Design History, 19(1), pp.1-10.

\footnotetext{
55 We currently work on two projects that examine grassroots digital fabrication. For more information see: http://grassrootsinnovations.files.wordpress.com/2014/01/gdf-briefing-1.pdf.
} 
Barnatt, C., 2013. 3D Printing: The Next Industrial Revolution, ExplainingTheFuture.com.

Barthes, R., 1973. Mythologies, Paladin.

Bauwens, M., 2006. The political economy of peer production, post-autistic economics review, 37(3), pp. 33-44.

Bell, G. \& Dourish, P., 2007. Yesterday's tomorrows: notes on ubiquitous computing's dominant vision. Personal and Ubiquitous Computing, 11, pp. 133-143.

Benkler, Y. \& Nissenbaum, H., 2006. Commons-based Peer Production and Virtue. Journal of Political Philosophy, 14(4), pp.394-419.

Birtchnell, T. \& Urry, J., 2013. 3D, SF and the future. Futures, 50, pp.25-34.

Birtchnell, T. \& Urry, J., 2012. Fabricating Futures and the Movement of Objects. Mobilities, pp.1-18.

Bohne, R., 2013. Machines for Personal Fabrication. In J. Walter-herrmann \& C. Büching, eds. FabLab of Machines, Makers and Inventors. Bielefeld: Transcript Verlag, pp. 163172.

Bollier, D., 2006. The growth of the commons paradigm. In C. Hess \& E. Ostrom, eds. Understanding knowledge as a commons: From theory to practice. Cambridge: MA: MIT Press.

Bookchin, M., 1978.Ecology and revolutionary thought. Antipode, 10-11(3-1), pp.21.

Bookchin, M., 1967. Towards a liberatory technology. Anarchy, 78(August).

Büching, C., 2013. A Universe of Objects. In J. Walter-Herrmann \& C. Büching, eds. FabLab of Machines, Makers and Inventors. Bielefeld: Transcript Verlag, pp. 105-122.

Burns, J., Gibbon, C., Rosembery, C. \& Yair, K.,, 2012. Craft in an Age of Change, Craft Council.

Burton, M., 2005. Design for Rapid Manufacturing: The impact of direct additive manufacturing on the industrial design process. Loughborough University.

Campbell, C., 2005. The Craft Consumer : Culture, craft and consumption in a postmodern society. Journal of Consumer Culture, 5(1), pp.23-42.

Carstensen, T., 2013. Gendered FabLabs? In J. Walter-Herrmann \& C. Büching, eds. FabLab of Machines, Makers and Inventors. Bielefeld: Transcript Verlag, pp. 53-64.

Chesbrough, H., Vanhaverbeke, W. \& West, J., 2006. Open innovation: researching a new paradigm, Oxford Univeristy Press. 
Coleman, G., 2010. The hacker conference: a ritual condensation and celebration of a lifeworld. Anthropological Quarterly, 83(1), pp.47-72.

Cooley, M., 1987. Architect or bee? The human price of technology, London: Hogarth Press.

Czarniawska-Joerges, B., 2007. Shadowing: and other techniques for doing fieldwork in modern societies, Copenhagen Business School Press.

Dafermos, G., 2012. Authority in peer production : The emergence of governance in the FreeBSD project. , (June), pp.1-12.

Delfanti, A., 2013. Biohackers: the politics of open science, Pluto Press.

Demil, B. \& Lecocq, X., 2006. Neither Market nor Hierarchy nor Network: The Emergence of Bazaar Governance. Organization Studies, 27(10), pp.1447-1466.

Dougherty, D., 2012. The Maker Movement. Innovations: Technology, Governance, Globalization, 7(3), pp.11-14.

Faludi, J., 2013. Is 3D printing an environmental win?, Greenbiz.com $19^{\text {th }}$ July 2013. Available at: http://www.greenbiz.com/blog/2013/07/19/3d-printing-environmentalwin\#sthash.YzaJ32ww.dpuf [Accessed February 27, 2013]

Gauntlett, D., 2013. Making is connecting, Polity Press.

Geels, F.W., 2011. The multi-level perspective on sustainability transitions: Responses to seven criticisms. Environmental Innovation and Societal Transitions, 1(1), pp.24-40.

Gershenfeld, N., 2005. FAB: the coming revolution on your desktop -from personal computers to personal fabrication, New York: Basic Books.

Gershenfeld, N., 2012. How to Make Almost Anything: The Digital Fabrication Revolution. Foreign Affairs, 91(6), pp.42-57.

Gjengedal, A., 2006. Industrial clusters and establishment of MIT FabLab at Furuflaten, Norway. $9^{\text {th }}$ International Conference on Engineering Education, 23-28 June, San Juan, Puerto Rico.

Gotkin, K., 2013. The Pleasure of the Hack: Locating Obsesssion in Tinkering. Available at: http://culturelab.asc.upenn.edu/files/2013/01/The-Pleasure-of-the-Hack.pdf [Accessed January 2014].

Grenzfurthner, J. \& Schneider, F.A., 2009. Hacking the space. Available at: http://www.monochrom.at/hacking-the-spaces/ [Accessed January 5, 2014].

Harvey, D., 1982. The limits to capital, Verso Books.

Hatch, M., 2013. The Maker Movement Manifesto, McGraw-Hill Professional. 
Haywood, D., 2012. The Ethic of the Code : An Ethnography of a "Humanitarian Hacking" Community, Journal of Peer Production, 3, pp.1-10.

Hine, C., 2000. Virtual ethnography, Sage Publications.

Hippel, E. Von, 2012. Comparing business and household sector innovation in consumer products: findings from a representative study in the United Kingdom. Management Science, 58.9, pp.1669-1681.

Hopkinson, N., Hague, R. \& Dickens, P., 2006. Rapid manufacturing: an industrial revolution for the digital age, Wiley-Blackwell.

Howe, J., 2009. Crowdsourcing: Why the Power of the Crowd is Driving the Future of Business, New York: Crown Business Publishing Group.

Huang, S.H. et al., 2012. Additive manufacturing and its societal impact: a literature review. The International Journal of Advanced Manufacturing Technology, 67(5-8), pp.11911203.

Hunsinger, J., 2011. The Social Workshop as PLE: Lessons from Hacklabs. Proceedings of the The PLE Conference, 10-12 July, Southampton, UK.

Illich, I., 1973. Tools for conviviality, Marion Boyar.

Jackson, A., 2010. Constructing at home: Understanding the experience of the amateur maker. Design and Culture, 2(1), pp.5-26.

Jones, R., Haufe, P., Sells, E., Iravani, P., Olliver, V., Palmer, C., \& Bowyer, A., 2011. RepRap the replicating rapid prototyper. Robotica, 29(01), pp.177-191.

Katterfeldt, E.-S., Zeising, A. \& Lund, M., 2013. Notes on Maker Culture. In J. Walterherrmann \& C. Büching, eds. FabLab of Machines, Makers and Inventors. Bielefeld: Transcript Verlag, pp. 123-126.

Kera, D., 2012. Hackerspaces and DIYbio in Asia : connecting science and community with open data, kits and protocols. Journal of Peer Production, 2(June), pp.1-8.

Kreiger, M. \& Pearce, J.M., 2013. Environmental Life Cycle Analysis of Distributed ThreeDimensional Printing and Conventional Manufacturing of Polymer Products. ACS Sustainable Chemistry \& Engineering, 1(12), pp.1511-1519.

Von Krogh, G. \& von Hippel, E., 2006. The Promise of Research on Open Source Software. Management Science, 52(7), pp.975-983.

Kuznetsov, S. \& Paulos, E., 2010. Rise of the Expert Amateur : DIY Projects, Communities, and Cultures. Proceedings of the $6^{\text {th }}$ Nordic Conference on Human-Computer Interaction: Extending Boundaries Pages, New York, USA. 
Lassiter, S., 2013. FabLabs: Thoughts and Remembrances. In J. Walter-Herrmann \& C. Büching, eds. FabLab OF Machines, Makers and Inventors. Bielefeld: Transcript Verlag, pp. 249-258.

Levy, S., 2001. Hackers: Heroes of the computer revolution, O'Reilly Media.

Lipson, H. \& Kurman, M., 2013. Fabricated: The New World of 3D Printing, Indiana: John Wiley \& Sons, Inc.

Magaudda, P., 2012. How to make a "Hackintosh". A journey into the "consumerization" of hacking practices and culture. Journal of Peer Production, 2(June), pp.1-8.

Marcus, G., 1995. Ethnography in/of the world system: the emergence of multi-sited ethnography. Annual Review of Anthropology, 24, pp.95-117.

Marres, N., 2012. Material participation: technology, the environment and everyday publics, Palgrave Macmillan.

Marston, L., 2011. Personal manufacturing NESTA, NESTA Hot Topics.

Marx, K., 1867. Capital, Volume I, Moscow: Progress Publishers.

Maxigas, 2012. Hacklabs and hackerspaces - tracing two genealogies. Journal of Peer Production, 2(June), pp.1-10.

McCue, T.J., 2012. Additive Manufacturing Will Change in the Next 5-10 Years. Available at: http://www.forbes.com/sites/tjmccue/2012/05/02/additive-manufacturing-willchange-in-the-next-5-10-years/ [Accessed January 5, 2014].

Mcquillan, D., 2012. From Free Software to Artisan Science Striation Critical pedagogy. Journal of Peer Production, 3(July), pp.1-7.

Miller, D., 2001. The poverty of morality. Journal of consumer culture, 1(2), pp.225-243.

Moilanen, J., 2011. Peer-production communities survey 2011. Available at: http://surveys.peerproduction.net/2012/07/mapping-hackers-diy-community-survey2012-results/ [Accessed January 5, 2014].

Morozov, E., 2014. A Critic At Large: Making it. The New Yorker.

Nierling, L., 2012. "This is a bit of the good life": Recognition of unpaid work from the perspective of degrowth. Ecological Economics, 84, pp.240-246.

Noble, D., 1979. America by design: Science, technology, and the rise of corporate capitalism, Oxford University Press Inc.

Noble, D., 1984. Forces of production, Oxford University Presss Inc. 
Nunez, J.G., 2010. Prefab the FabLab: rethinking the habitability fabrication lab by including fixture-based components. Massachusetts.

O'Mahony, S., 2003. Guarding the commons: how community managed software projects protect their work. Research Policy, 32(7), pp.1179-1198.

Olson, R., 2013. A Boon or Bane? The Environmental Forum, 30(6), pp.34-38.

Ostrom, E. \& Hess, C., 2007. Private and common property rights. Available at SSRN: http://dx.doi.org/10.2139/ssrn.1304699.

Pearce, J.M., Blair, C.D., Laciak, K.J., Andrews, R., Nosrat, A. \& Zelenika-Zovko, I.,, 2010. 3-D Printing of Open Source Appropriate Technologies for Self-Directed Sustainable Development. Journal of Sustainable Development, 3(4), pp.17-30.

Petschow, U., Dickel, S. \& Steinfeldt, M., 2014. Potenziale von neuen Technologien, dezentraler und personalisierter Produktion vor dem Hintergrund des Leitbildes kohlenstoffarmer Wirtschaft. Schlussbericht IOEW.

Prug, T., 2013. A note on evaluation processes for social phenomena with ambitious claims: a response to Stefan Meretz. Journal of Peer Production, (1), pp.1-2.

Ree, R., 2011. 3D Printing: Convergences, Frictions, Fluidity. Master thesis, Univeristy of Toronto.

Rifkin, J., 2011. The third industrial revolution: how lateral power is transforming energy, the economy, and the world, Palgrave Macmillan.

Rip, A. \& Kemp, R., 1998. Technological change. In S. Rayner \& E. L. Malone, eds. Human choices and climate change. Volume 2: resources and technology. Columbus, Ohio: Bateller.

Robben, B., 2013. The History of Production with Computers. In J. Walter-herrmann \& C. Büching, eds. FabLab of Machines, Makers and Inventors. Bielefeld: Transcript Verlag, pp. 127-138.

Rosner, D.K., 2013. Making Citizens, Reassembling Devices: On Gender and the Development of Contemporary Public Sites of Repair in Northern California. Public Culture, 26(1 72), pp.51-77.

Sabel, C. \& Piore, M., 1984. The second industrial divide. Nova lorque: Basic Books.

Scholz, T., 2013. Digital labour: the internet as playground and workplace, Routledge.

Schor, J.B., 2010. Plenitude: The New Economics of rue Wealth, New York: Penguin Press. 
Schot, J. \& Geels, F.W., 2008. Strategic niche management and sustainable innovation journeys: theory, findings, research agenda, and policy. Technology Analysis \& Strategic Management, 20(5), pp.537-554.

Schumacher, F.W., 1973. Small is beautiful, London: Blond and Briggs.

Sellen, A. \& Harper, R., 2003. The myth of the paperless office, MIT Press.

Seyfang, G. \& Smith, A., 2007. Grassroots innovations for sustainable development: Towards a new research and policy agenda. Environmental politics, 16(4), pp.584-683.

Simpson, T., Siddique, Z. \& Jiao, R., 2006. Product platform and product family design: methods and applications, Springer.

Smith, A. 2005. The alternative technology movement: an analysis of its framing and negotiation of technology development. Research in Human Ecology, 12(2), pp.106119.

Smith, A., 2014. Socially useful production. STEPS Working Paper Series, Working Paper 58, STEPS Centre, Brighton.

Smith, A., Hielscher, S., Dickel, S. Soederberg, J. \& van Oost, E., 2013. Grassroots digital fabrication and makerspaces: reconfiguring, relocating and recalibrating innovation? SPRU Working Paper Series, SWPS 2013-02.

Smith, A. \& Raven, R., 2012. What is protective space? Reconsidering niches in transitions to sustainability. Research Policy, 41(6), pp.1025-1036.

Smith, A., Stirling, A. \& Berkhout, F., 2005. The governance of sustainable socio-technical transitions. Research Policy, 34(10), pp.1491-1510.

Söderberg, J., 2013. Automating amateurs in the 3D printing community: connecting the dots between "deskilling" and "user-friendliness." Work Organisation, Labour and Globalisation, 7(1), pp.124-139.

Söderberg, J., 2011. Free space optics in the Czech wireless community: shedding some light on the role of normativity for user-initiated innovations. Science Technology and Human Values, 36, p.423.

Söderberg, J., 2010a. Misuser Inventions and the Invention of the Misuser: Hackers, Crackers and Filesharers. Science as Culture, 19(2), pp.151-179.

Söderberg, J., 2010b. Reconstructivism versus Critical Theory of Technology: Alternative Perspectives on Activism and Institutional Entrepreneurship in the Czech Wireless Community. Social Epistemology, 24(4), pp.239-262. 
Stirling, A. 1999. The appraisal of sustainability: some problems and possible responses. Local Environment: The International Journal of Justice and Sustainability, 4(2), pp. 111135.

Sylvester, A. \& Doering, T., 2013. Urban Development with FabLans. In J. Walter-herrmann \& C. Büching, eds. FabLab of Machines, Makers and Inventors. Bielefeld: Transcript Verlag, pp. 223-230.

Tapscott, D. \& Williams, A., 2008. Wikinomics: How mass collaboration changes everything, Portfolio Trade.

Thorpe, A., 2012. Architecture \& Design versus Consumerism: How Design Activitism Confronts Growth, Routledge.

Tilly, C., 2005. Social Movements, 1768-2004. Paradigm.

Toffler, A., Longul, W. \& Forbes, H., 1981. The third wave, Pan Books.

Troxler, P., 2010. Commons-based peer-production of physical goods: is there room for a hybrid innovation ecology? Paper presented at The 3rd Free Culture Research Conference, Berlin, October 8-9.

Troxler, P., 2011. Libraries of the Peer Production Era. In B. van Abel et al., eds. Open Design Now: Why Design Cannot Remain Exclusive. Amsterdam: BIS Publisher.

Troxler, P., 2013. Making the Third Industrial Revolution - The Struggle for Polycentric Structures and New Peer-Production Commons in the FabLab Community. In J. WalterHerrmann \& C. Büching, eds. FabLab of Machines, Makers and Inventors. Bielefeld: Transcript Verlag, pp. 181-198.

Truffer, B., 2003. User-led Innovation Processes: The Development of Professional Car Sharing by Environmentally Concerned Citizens. Innovation: The European Journal of Social Science Research, 16(2), pp.139-154.

Turner, F., 2010. From counterculture to cyberculture: Stewart Brand, the Whole Earth Network, and the rise of digital utopianism, Univeristy of Chicago Press.

Walter-Herrmann, J., 2013. FabLabs - A Global Social Movement. In J. Walter-Herrmann \& C. Büching, eds. FabLab of Machines, Makers and Inventors. Bielefeld: Transcript Verlag, pp. 33-46.

Walter-Herrmann, J. \& Büching, C., 2013. Notes on FabLabs. In J. Walter-Herrmann \& C. Büching, eds. FabLab of Machines, Makers and Inventors. Bielefeld: Transcript Verlag, pp. 9-26.

Walter-herrmann, J. \& Büching, C., 2013. Fablab of Machines, Makers and Inventors, Bielefeld: Transcript Verlag. 
Weinberg, M. \& Knowledge, P., 2010. It Will be Awesome If They Don't Screw it Up: 3D Printing, Intellectual Property, and the Fight Over the Next Great Disruptive Technology, Public Knowledge.

Wood, N. \& Rust, C., 2003. Designing for tacit learning: An investigation of design strategies for multimedia supported learning in the crafts. Available at: http://shura.shu.ac.uk/958/ [Accessed March 11, 2014].

Wood, N., Rust, C. \& Home, G., 2009. A Tacit Understanding: The Designer's Role in Capturing and Passing an the Skilled Knowledge of Master Craftsmen. International Journal of Design, 3(3), pp.65-78.

Woodward, I., 2009. Material culture and narrative: Fusing myth, materiality and meaning. In P. Vannini, ed. Material culture and technology in everyday life. New York: Peter Lang Publishing, pp. 59-72.

Zeitlyn, D., 2003. Gift economies in the development of open source software: anthropological reflections. Research Policy, 32(7), pp.1287-1291. 


\section{Recent papers in the SPRU Working Paper Series:}

SWPS 2013-14. Diego Chavarro, Puay Tang, and Ismael Rafols. November 2013. "Interdisciplinarity and research on local issues: evidence from a developing country".

SWPS 2013-15. Paul Nightingale. November 2013. "Schumpeter's Theological Roots? Harnack and the origins of creative destruction".

SWPS 2013-16. Mariana Mazzucato and Stuart Parris. November 2013. "High growth firms, innovation and competition: the case of the US pharmaceutical industry".

SWPS 2013-17. Hakim Hammadou, Sonia Paty, and Maria Savona. December 2013. "Strategic interactions in public R\&D across European countries: A spatial econometric analysis".

SWPS 2014-01. Nicola Grassano and Maria Savona. January 2014. "Productivity in services twenty years on. A review of conceptual and measurement issues and a way forward".

SWPS 2014-02. Florian Kern, Adrian Smith, Chris Shaw, Rob Raven and Bram Verhees. February 2014. "From laggard to leader: Explaining offshore wind developments in the UK."

SWPS 2014-03. Andy Stirling . March 2014. "Transforming Power: social science and the politics of energy choices."

SWPS 2014-04. Alex Coad, Gabriele Pellegrino and Maria Savona. March 2014. "Don't Stop Me Now: Barriers to innovation and firm productivity."

SWPS 2014-05. Antonio Messeni Petruzzelli, Vito Albino, and Daniele Rotolo. April 2014.

"Determinants of Patent Citations in Biotechnology: An Analysis of Patent Influence Across the Industrial and Organizational Boundaries."

SWPS 2014-06. Andy Stirling. April 2014. "From Sustainability to Transformation: Dynamics and diversity in reflexive governance of vulnerability."

SWPS 2014-07. Ralitsa Petrova Hiteva and and Tomas Maltby. April 2014." Standing in the way by standing in the middle: the case of state-owned natural gas intermediaries in Bulgaria."

\section{SPRU}

Science and Technology

Policy Research
SPRU

Science and Technology Policy Research

University of Sussex

Falmer, Brighton, BN1 9SL, UK

www.sussex.ac.uk/spru 